THE USE OF AWARENESS DISPLAYS FOR ROLE CLARITY IN DISTRIBUTED WORKGROUPS

\author{
A Dissertation \\ Presented to the Faculty of the Graduate School of \\ Cornell University \\ In Partial Fulfillment of the Requirements for the Degree of \\ Doctor of Philosophy
}

by

Lindsay Lee Reynolds

August 2013 
(C) 2013 Lindsay Lee Reynolds 


\title{
THE USE OF AWARENESS DISPLAYS FOR ROLE CLARITY IN DISTRIBUTED WORKGROUPS
}

\author{
Lindsay Lee Reynolds, Ph.D.
}

Cornell University 2013

Geographically distributed workgroups have potential for improving collaborative work, but can be challenging. One challenge is identifying which group members are responsible for specific elements of a task when group members' actions are not easily observable. As such, individuals participating in geographically distributed work may be more susceptible to role ambiguity, which is an unclear understanding of one's own or others' roles within the group. Visual awareness displays may help mitigate role ambiguity by making otherwise unclear information more apparent, but the design of the awareness display may also impact how role ambiguity is experienced. Specifically, tailoring displays to highlight only role-relevant information and abstract other information may be more beneficial than displays that either highlight or abstract all information. This study explores the effect of awareness display type on role ambiguity and communication about role information on geographically distributed individuals collaborating on a video game task using an experimental design. One hundred eighty six participants were assigned to groups of three individuals and completed a fifteen-minute task in the online multiplayer game Neverwinter Nights, in which they had access to either a tailored, abstract, or detailed visual awareness display. Their performance and communication were recorded and analyzed along with surveys measuring role ambiguity and objective role understanding. The results indicated that individuals most accurately identified group members' roles when they had access to the detailed display, but that awareness display type did not have an effect on feelings of role ambiguity. In terms of performance, there was an overall trend toward the detailed display being best for facilitating performance in on the less collaborative aspect of the task, although there was an interaction such that more frequent video game players performed better than less frequent players, but only when they had access to the tailored display. For the more collaborative aspect of the task, however, the abstract display best facilitated performance. Awareness display type did not impact any type of communication between group members. Future work in this area can explore different awareness display configuration types on role ambiguity, or the impact of prior experience on interpreting these displays. 


\section{BIOGRAPHICAL SKETCH}

Lindsay Reynolds grew up in Riverside, California. She obtained a B.A. in Psychology and Sociology from UCLA in 2005. After working as a K-12 substitute teacher, she pursued graduate studies at Cornell University, where she earned a M.S. in Communication in 2012. Her research focuses on understanding how communication impacts aspects of both work and social collaboration in mediated contexts. 
To my grandparents, for always believing in me. 


\section{ACKNOWLEDGEMENTS}

Faculty, friends, and family members have helped me to complete this dissertation, and I would like to express my gratitude to them for their tremendous amount of support and encouragement. First and foremost, I want to thank my advisor, Jeremy Birnholtz, for his encouragement, generosity, and patience, and for providing me with an excellent atmosphere for doing research. He allowed me the freedom to pursue my interests but was always available to provide useful and insightful feedback and advice along the way. His guidance has made this a rewarding journey. As a committee member and instructor, Sue Fussell has pushed me to be a stronger thinker and researcher, and I greatly appreciate her input and support throughout my time at Cornell. I'm glad to have had Kathleen O'Connor on my committee, as she provided a novel perspective on my work as well as a refreshing attitude toward the dissertation process. Jeff Hancock was not only generous with his time and expertise as a committee member but went the extra mile in supporting me during my dissertation year, for which I am deeply grateful.

I am also grateful to the Neverwinter Nights community for providing advice and assistance with the experimental setup and conditions. In particular, I want to thank The Amethyst Dragon for allowing me to use his Health Bar and Icon modifications, Kato_Yang for creating the LifeBar and explaining the intricacies of the game and its modifications to me, and Baaleos for teaching me how to script and implement visual effect modifications. I also greatly appreciate the efforts of John Kent, Jessie Taft, Eric Tan, and Vicky Zhu in helping me develop the experiment, collect data, and code chat transcripts.

I've also had the good luck to meet some amazing friends along the way. I'm glad to have had Harmonie Farrow around early on to help me adjust to life at Cornell and in Ithaca. More recently, the members of Team Loco have always been there for a laugh and a drink to 
help celebrate the good times and forget the bad ones. I looked forward to our happy hours all week. And of course, I can't mention friends without thanking Victoria Schwanda Sosik, Madeline Smith, and Bobby Beaton, my fellow members in the "GLITTER Project." Not only have they been ridiculously supportive and put up with all sorts of my crazy, they went above and beyond the call of duty to make sure that I made it through April and May 2013 in one piece, and I owe them big time for that.

My family has been a source of strength and support for me throughout my life. I want to thank my grandparents Everett and Betty Spriggs for taking an extraordinary interest in my education and for doing so much to help me succeed, and Roy and Maxine Reynolds for their comfort and support. My mom, Claudia Spriggs, has taught me by example about dedication and perseverance, and cares so deeply about my work (even when she isn't totally sure what I do). I'm glad I picked you, and stickettub. My siblings Reid and Cathy Reynolds and Kylie Reynolds are overall awesome people, and I couldn't have asked for better siblings. My cat Kodo has been a loyal companion and sat dutifully by my side throughout the writing of this document. And last, but certainly not least, I want to thank David Mortier. During my time in graduate school, he's been my cheerleader, sounding board, comedic relief, guinea pig, shoulder to cry on, and better half. I couldn't have done this without him. 


\section{TABLE OF CONTENTS}

$\begin{array}{ll}\text { BIOGRAPHICAL SKETCH } & \text { iii }\end{array}$

DEDICATION $\quad$ iv

ACKNOWLEDGEMENTS $\quad$ v

TABLE OF CONTENTS vii

LIST OF FIGURES $\quad$ ix

LIST OF TABLES $\quad$ X

CHAPTER 1 - INTRODUCTION 1

CHAPTER 2 - AWARENESS DISPLAYS 5

CHAPTER 3 - ROLES AND ROLES AMBIGUITY $\quad 8$

Roles $\quad 8$

Role Episode Model 9

Role Ambiguity 12

Using MMOGs to Study Role Ambiguity 15

CHAPTER 4 - MMOGS 16

What are MMOGs? 16

$\begin{array}{ll}\text { Collaboration in MMOGs } & 17\end{array}$

Role Differentiation and Ambiguity in MMOGs $\quad 18$

$\begin{array}{ll}\text { Awareness Displays in MMOGs } & 19\end{array}$

CHAPTER 5 - HYPOTHESES 25

CHAPTER 6 - METHOD $\quad 30$

$\begin{array}{ll}\text { Participants } & 30\end{array}$

Game Environment 31

Task 31

Roles $\quad 32$ 
$\begin{array}{ll}\text { Procedure } & 34\end{array}$

Experimental Conditions $\quad 34$

Data Collection and Analysis $\quad 41$

Performance $\quad 41$

Questionnaires $\quad 42$

$\begin{array}{ll}\text { Transcripts } & 42\end{array}$

CHAPTER 7 - RESULTS

Role Ambiguity $\quad 43$

Performance $\quad 58$

Task and Social Satisfaction $\quad 65$

$\begin{array}{ll}\text { Communication } & 67\end{array}$

CHAPTER 8 - DISCUSSION

Role Ambiguity $\quad 71$

$\begin{array}{ll}\text { Performance } & 74\end{array}$

$\begin{array}{ll}\text { Communication } & 76\end{array}$

$\begin{array}{ll}\text { Implications for Design } & 78\end{array}$

Research Limitations $\quad 79$

$\begin{array}{ll}\text { Future Work } & 79\end{array}$

$\begin{array}{lr}\text { Conclusion } & 80\end{array}$

APPENDIX 1 - TASK INTRODUCTION 82

APPENDIX 2 - PLAYER REFERENCE SHEETS 83

APPENDIX 3 - QUESTIONNAIRES 92

$\begin{array}{ll}\text { APPENDIX } 4 \text { - CODING SCHEME } & 100\end{array}$

$\begin{array}{ll}\text { REFERENCES } & 103\end{array}$ 


\section{LIST OF FIGURES}

$\begin{array}{lll}\text { Figure } 1 & \text { The Role Episode Model } & 10\end{array}$

$\begin{array}{lll}\text { Figure } 2 & \text { Rainbow Colorized Health Bar } & 37\end{array}$

$\begin{array}{lll}\text { Figure } 3 & \text { Abstracted Health Bar } & 38\end{array}$

$\begin{array}{lll}\text { Figure } 4 & \text { Lifebar } & 39\end{array}$

$\begin{array}{lll}\text { Figure } 5 & \text { Damage dealt visual effect } & 39\end{array}$

$\begin{array}{lll}\text { Figure } 6 & \text { Obvious goblin target visual effect } & 40\end{array}$

$\begin{array}{lll}\text { Figure } 7 & \text { Subtle goblin target effect } & 40\end{array}$

Figure $8 \quad$ Colorized ability icons for the tailored and detailed 41 conditions

Figure $9 \quad$ Percent of Correct Responses to "During Task Survey" at 47 Completion of Task

Figure $10 \quad$ Average Composite Score on the Role Ambiguity Scale by 49 Participant Role

Figure $11 \quad$ Number of Player Deaths by Display Condition $\quad 60$

Figure $12 \quad$ Overall Player Deaths by Time Period 62

Figure $13 \quad$ Player Deaths by Time Period and Awareness Display 64 Condition 


\section{LIST OF TABLES}

Table $1 \quad$ Description of the tailored display 36

Table 2 Description of the abstract display 36

Table $3 \quad$ Description of the detailed display 36

Table $4 \quad$ Comparisons of the Percentage of Correct Responses on the 47 Final "During Task Survey"

Table $5 \quad$ Descriptives for the Percentage of Correct Responses on 52 "During Task Survey" Time Periods 1-3

Table 6 Percentage of Correct Responses to "During Task Survey" Times 1-3

Table $7 \quad$ Magnitude of Responses to the "During Task Survey" Times $1-3$

Table $8 \quad$ Self vs. Othe Assessment on "During Task Survey" after Time Periods 1-3

Table $9 \quad$ Player Deaths by Time Period and Awareness Display Condition 


\section{CHAPTER 1}

\section{INTRODUCTION}

With the proliferation of Internet technology, people are increasingly forming groups with others across the world in order to collaborate in a variety of contexts. These groups, sometimes called distributed work groups, are "group[s] of individuals whose members and resources may be dispersed geographically and institutionally, yet who function as a coherent unit through the use of cyberinfrastructure" (Cummings, Finholt, Foster, and Kesselman, 2008, pg. 9). In some contexts, members of these groups work individually and share only finished products (e.g., reports), while in other situations group members work together in a shared virtual space. For example, military and rescue groups use online simulators to practice teamwork for real world exercises (Hussain and Ferguson, 2005) and researchers can manipulate scientific instruments and models online (Sonnenwald, Maglaughlin, and Whitton, 2004). There is a long history of research that examines and evaluates coordination and communication among members of various types of distributed groups, with the interest of better understanding and improving group work under these conditions.

However, research on the performance of distributed groups has found that distributed groups perform often more poorly than collocated ones (e.g., Straus and McGrath, 1994; Baltes, Dickson, Sherman, Bauer, and LaGanke, 2002; Sins, Savelsbergh, van Joolingen, and van Hout-

Wolters, 2011). This study aims to explore one possible reason for the challenges of working across distances: group members may find it more difficult to identify the tasks they must perform to help the group complete its activity. 
In addition to the real world applications noted above, these types of groups are also formed among players of Multi-Player Online Games (MMOGs), which are the focus of this study. In this situation, although players may be located around the world, their in-game avatars convene in the game environment in order to jointly complete activities, such as killing enemy monsters. These collaborations are highly interdependent, and take place in real-time. At first glance, MMOGs appear to have very little in common with workplace environments. For example, these groups differ from many other types of distributed groups in that individual group members are represented by avatars in a virtual space, and thus can interact with others differently than is allowed in other situations (e.g., collaborative document writing). Furthermore, tasks in MMOGs can only be completed in a virtual space, so there is no face-toface equivalent of these activities. However, some have argued that despite the numerous surface differences between MMOGs and work settings, online video games are applicable to real life collaborative work environments, and have used these games as teamwork building tools (e.g., Hussain and Ferguson, 2005). Additionally, research on collaborative play in MMOGs has some clear parallels to research on collaborative work, especially in terms of participants' experience and familiarity at performing the given tasks (Yee, 2006a), the way recurring groups assign roles to players (Chen, 2009), and role ambiguity and its effects on group members (Bardzell, Bardzell, Pace, \& Reed, 2012.) And as more and more work is being conducted remotely, there is still value in learning about collaboration in online only tasks.

In groups with multiple people, it is sometimes hard to determine which group members are responsible for performing which components of an activity, which can cause "role ambiguity," which is confusion or uncertainty about tasks one should be doing (Kahn, Wolfe, Quinn, Snoek, and Rosenthal, 1964). 
Using an MMOG group as an example, a group of players may form in order to defeat a particularly challenging enemy monster. In order to be successful at completing that activity, there are a set of smaller tasks which must be completed (e.g., inflicting damage to the monster, preventing the monster from inflicting damage on the players, ensuring no other monsters attack the group). However, there may be confusion among the players about which one or ones of those tasks they are responsible for completing. It may be especially hard to determine what tasks one is responsible for when the actions of group members are not always directly visible to other group members, or when roles are emergent (as opposed to having roles assigned by a leader). As role clarity is an important component of successful and enjoyable group work (Kahn et al., 1964), it is important to better understand how to promote role clarity during collaborations. One important factor for the promotion of role clarity is the visibility of the actions of group members to others. Kahn et al. (1964) noted in their study of collocated group work that individuals can gather information by observing the visible actions or conversations of others, which have been shown to help the observer figure out which tasks he should be doing; in contrast, during a collaboration in an MMOG, the actions of other group members are less visible to an observer, and as a result gathering this information about others in this environment is challenging. However, MMOG players may be able to gather information about the otherwise invisible actions of others through the use of awareness displays, which provide information about the status and activities of others. Making use of awareness displays in this way can explore how visual awareness displays, particularly ones which selectively present information to group members, may provide clues to group members about which tasks they should be performing, which can reduce role ambiguity in groups where behaviors would otherwise be invisible. Exploring how various configurations of awareness displays can help reduce role 
ambiguity in distributed groups is the focus of this study. Additionally, awareness displays are traditionally used for assisting group members with real time collaboration and updating them on the status of group members; this provides an opportunity to explore whether these displays can also be used for helping group members learn their role in a group and apply that knowledge to future group work.

Chapters 2, 3, and 4 review previous research on awareness displays, previous research on roles, then how awareness displays could factor in forming role expectations and learning roles, and how these factors are manifested within MMOGs. Chapter 5 presents hypotheses regarding role ambiguity, performance, task and social satisfaction, and communication. Chapter 6 outlines the experimental setup, condition manipulations, and data collection methods used in this study. The results of the study, which no support for the hypotheses regarding role ambiguity and communication, and limited support for the hypotheses regarding performance, are presented in Chapter 7. Chapter 8 discusses the research and design implications of this work. 


\section{CHAPTER 2}

\section{AWARENESS DISPLAYS}

Awareness displays are part of a long line of research that aims to understand the role of awareness about fellow group members in facilitating successful collaborative work (e.g., Heath and Luff, 1992; Bly, Harrison, and Irwin, 1993). Typically, awareness displays have been used for assistance in real-time coordination, as they provide updates about the status of remote collaborators, but this study explores another way in which these displays may be used to aid collaborative groups: by providing information to assist in behaviors to reduce role ambiguity.

The idea of "awareness" is a central concept for collaborative work, and is a particular focus in the area of Computer Supported Collaborative Work (Schmidt, 2002). Awareness is, generally, the state of knowing who collaborators are, what they are doing, what they have done, and anticipating what they will do (Schmidt, 2002).

Much work on awareness draws off of the cognitive models presented by Neisser (1976) and Endsley (1995). Neisser's (1976) perception-action cycle, one of the early models regarding awareness, shows the cyclical relationship between an environment, one's knowledge of that environment, and the process of gathering information. Endsley (1995) puts forth a three-part model of situation awareness (SA), or the state of knowledge derived from the perception and integrated understanding of elements in a dynamic environment, and each part of the model becomes increasingly complex. In the first part of this model, one must perceive the characteristics of significant elements in the environment, such as an element's status, attributes, or dynamics. Next, one builds from the individual elements perceived by synthesizing those 
elements in order to create a more complete understanding of the environment and the significance of the elements to the individual's goals for the task. Lastly, one further builds on past perceptions and understanding of the environment in order to anticipate how those elements may change in the future.

Typically, these cognitive models have been primarily used as a way to understand how people anticipate changes in the environment and make decisions about the near future. However, these ideas may also be useful for understanding how people learn how they fit into an environment with others, and learn about their role in the group for future activities.

An important consideration in terms of the design of these types of systems is providing the most (and most useful) information to group members (Gutwin and Greenberg, 2002). Therefore, the type of awareness display used can vary in terms of how information is presented to different group members. One way to categorize the differences between the ways in which awareness information is displayed is by the degree to which views and information is shared among group members. These types of systems can either display information such that "What You See Is What I See" (WYSIWIS), Relaxed "What You See Is What I See," or "What You See Is Not What I See" (WYSINWIS).

What You See Is What I See (WYSIWIS) systems support both the same views of the target (e.g., document, focal point), as well as shared views of each of the collaborators such that there is a total synchronization of each person's view within a shared workspace. However, these types of displays can lead to high overhead costs and tensions between group members who want changes to the display (Zhu, 2004). Relaxed WYSIWIS systems are variants of traditional WYSIWIS systems (e.g., Stefik et al., 1987 and Benford et al., 2001), which do not require the same strict synchronization that is the hallmark of WYSIWIS. However, one disadvantage of 
Relaxed WYSIWIS systems is that it can be challenging to know what types of information other group members are currently viewing, which can make it difficult to discuss information with others (Gutwin and Greenberg, 2002).

Lastly, there are What You See Is Not What I See (WYSINWIS) type systems (Zhu, 2004), which stem from the idea that in a group, different people have different responsibilities and collaborative tools should support these differences. WYSINWIS systems highlight the differences between people in a group, because as people have different roles and viewpoints in the real world, these systems emphasize that no one's view of a shared object is actually the same as anyone else's. As such, role concepts are an important factor in WYSINWIS systems, and information is tailored to individuals accordingly.

Literature regarding roles in various types of virtual and distributed groups is sparse in the $\mathrm{CSCW}$ or $\mathrm{CHI}$ fields, and the research which does explore roles in these fields primarily explores the technical requirements for supporting a variety of tools for group members with different roles (e.g., Smith et al., 1998; Gudzial et al., 2000). One ethnographic study on groups in MMOGs briefly discussed how players talk about their roles in a group, and the consequences of unclear understandings and expectations about roles (Chen, 2009). As a result, the present study draws heavily from organizational literature regarding role ambiguity, and applies it to MMOG groups. 


\section{CHAPTER 3}

\section{ROLES AND ROLE AMBIGUITY}

\section{Roles}

In many group work situations, there is a division of labor for the tasks which comprise the group's activity, which leads to different roles. There are a variety of different definitions of the term "role," but many of them refer to the set of actions and behaviors that a given person is expected to undertake (e.g., Biddle and Thomas, 1979; Bostrom, 1980), and generally refer to a long-term state of being as opposed to referring to the current tasks that a person is performing (e.g., Hughes, 1958). Roles are one of the key features of a multi-person work group, and they provide continuity in organizations (Kahn, Wolfe, Quinn, Snoek, and Rosenthal, 1964; Goffman, 1961). Roles are often associated with individuals in one of two ways. Most commonly in structured organizational settings, roles are assigned to group members by someone in a leadership position (e.g., manager, team captain, etc.), but roles can also arise organically (particularly when the leadership structure of a group is less clear) as a function of emerged practice or social convention (Strauss, 1985). Individual roles within a group are often interconnected, such as reporters, editors, and photographers working together to create news articles (Johnson and Johnson, 1997), and form what is called a role set (Kahn et al., 1964). Lastly, the individual that assumes a role often personalizes that position, such that two people in the same role will often produce different expressions of that role (Graen, 1976).

The individuals that occupy the roles which form a role set have role expectations about both their role as well as the other roles in their role set. Role expectations are the ideas that 
individuals have about which tasks and responsibilities are covered by various roles, including one's own (Kahn et al., 1964). As role expectations about a given role are held by all individuals holding roles in a role set, making these expectations clear to the person performing the role is a process which is distinct from the role assignment process (as that process may or may not involve all people associated with the role set).

\section{Role Episode Model}

The classic and enduring conceptual model for understanding individual roles within a group and how role information is communicated to individuals is the "role episode model," which was proposed by Kahn et al. (1964) and describes how role expectations are conveyed and experienced within a group. This model was chosen as the crux for this discussion on roles and role ambiguity in part because of its continued status as the defining work in this area. This model has a few advantages over other approaches to explaining roles in organizations. First, it is a basic model which provides clear examples of the factors which may cause role ambiguity while allowing for the integration of other theories and models (Mintzberg, 1994), which is ideal for combining research on roles and visual awareness displays. Another reason this model is most appropriate for this study is because it captures global perceptions of job stress and can be applied to a wide variety of job types (Dougherty and Prichard, 1985). Furthermore, while other conceptual work has expanded the model (e.g., Van Sell, Brief, and Schuler, 1981, Singh, 1998) the core elements of the model have remained intact and are sufficient for identifying the numerous ways in which role ambiguity may originate. While it is called the role episode model, Kahn et al. (1964) actually describe a cyclical process by which individuals receive information about, clarify, and potentially negotiate their role with and in relation to others with whom they share a group (Figure 1). 

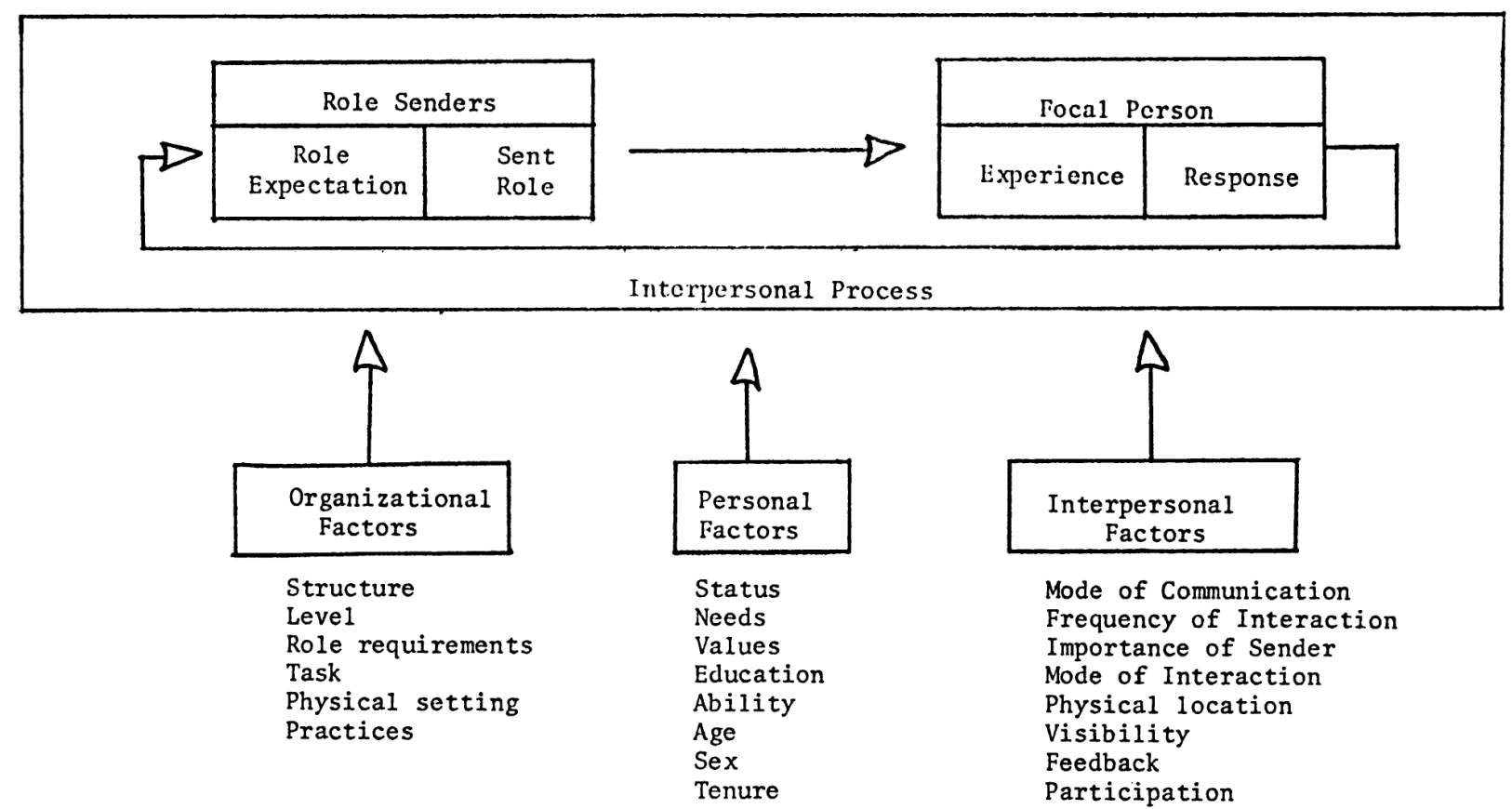

Figure 1: The Role Episode Model (Van Sell et al., 1981).

In the model, the person who is performing the role in question is called the "focal person," and all other people associated with the role set are called "role senders." An episode starts with the existence of a set of various role expectations (which originate from organizational structure, the specialization of a focal person, etc.,), which are held by role senders about a focal person and his or her behavior on the job. Although role expectations often have antecedents which occur outside of the bounds of the model, these expectations are further developed by role senders based on the experiences they have with regard to a focal person and his execution of his role, and have perceptual, cognitive, and evaluative components. The model acknowledges that role senders are described as a single unit for the sake of simplicity, when in reality each role sender develops a unique role expectation with regard to a focal person. These expectations, perceptions, and evaluations result in the "sent role," which are the messages that role senders transmit (either directly or indirectly) to a focal person regarding their expectations 
of the focal person's responsibilities within a role (e.g., "next time, make sure to ask the customer whether they would like a receipt with their order," "will you enter that into the database?," "great job on handling those phone calls this morning.") Sent role transmissions may either indicate that a focal person is acting in accordance with a role sender's expectations or that the focal person is not acting in accordance with expectations, in which case the sent role may attempt to influence the focal person to more closely conform with a role sender's expectations. Kahn et al. (1964) are careful to distinguish between role senders' internal role expectations and their external sent role messages, identifying that what any given role sender transmits to a focal person may not align exactly with what he or she actually thinks in terms of role expectations (and in fact, this is one way in which role ambiguity may occur).

The focal person receives these sent role messages from role senders, which leads to perceptions and expectations of his own regarding his role (again, keeping in mind that the focal person's perception of the sent role message may not be identical to either the role sender's role expectation or sent role message). Kahn et al. (1964) argue that these perceptions have the greatest impact on a focal person's experience and understanding of their role of any of the elements of the model. For example, if role senders are generally supportive of a focal person's present performance and this is transmitted properly, than the focal person should feel satisfaction and confidence in his job performance. But if sent role messages are strongly negative, contradictory, or poorly transmitted, the focal person is likely to feel confused or insecure about his job performance. This experience, whether it is positive or negative, leads to a response by the focal person, which can manifest in terms of compliance with role expectations or coping mechanisms to negotiate tensions with role pressures (in situations where a focal person receives different or conflicting role expectations from others). At this point, the model 
becomes cyclical, as there is a feedback loop such that the way in which a focal person responds to sent role perceptions influences the role senders in terms of their perceptions and evaluations of the focal person's role and performance of that role (e.g., if a focal person responds by complying with requests his role performance may be evaluated more positively by role senders).

As illustrated in Figure 1, the role episode process may be affected by personal factors (e.g., either the role sender or focal person's history within a group), interpersonal factors (e.g., physical location of the role sender or frequency of their interaction with the focal person), or organizational factors (e.g., traditional group practices, physical setting of the task), as any of these factors can impact the role senders' or focal person's perceptions or responses, as well as the interactions between them during any given episode. As a result, the role episode process by which role senders' expectations are transmitted and perceived by a focal person does not always unfold as clearly as described. When this process is impacted or interrupted it can result in role senders holding unclearly defined role expectations for a focal person or clearly defined role expectations being unclearly transmitted to a focal person.

\section{Role Ambiguity}

If, for whatever reason, role expectations are not clearly defined for a focal person, he may experience role ambiguity, which is described as an instance in which "the single or multiple roles which confront an individual [are] not clearly articulated in terms of behaviors or performance levels expected" (Van Sell et al., 1981). Role ambiguity in groups can be either objective (in terms of the objective characteristics of a role and how they are conveyed) or subjective (in terms of the reactions of the focal person) (Lichtman and Hunt, 1973). However, because of the challenging nature of studying objective role ambiguity, much of the research that has been done has been regarding subjective role ambiguity (Van Sell et al., 1981). 
Empirical research exploring role ambiguity has found that it leads to a number of negative consequences for focal people as well as the groups to which they belong. For example, Jones (2007) found that increased role ambiguity resulted in individuals feeling anxious and afraid to perform any tasks or assume any responsibilities. Caplan and Jones (1975) found that role ambiguity led to reduced group performance, increased negative attitudes toward role senders by focal people, and increased tension, anxiety, and depression among focal people. Slatterya, Selvarajanb, and Andersonic (2008) found that increased role ambiguity was associated with lower job satisfaction for focal people who were in temporary positions. Fisher and Gitelson (1983) conducted a meta-analysis of correlational studies involving role ambiguity, which supports the claims that increased role ambiguity is associated with reduced satisfaction with co-workers and job-related tension. More recently, Judeh (2011) found that role ambiguity is a mediator of the relationship between employee socialization and organizational commitment, and Beauchamp (2002) found that increased role ambiguity was associated with decreased performance in group athletic contexts.

Kahn et al. (1964) note that the physical location of group members is an important part of the role episode model, in that some of the interpersonal and organizational factors which can impact the transmission of role expectations were specifically about location (e.g., the visibility of role senders and focal people), while others were indirectly related to location (such as the mode of communication of role expectations). While Kahn et al. (1964) talk about reduced visibility of group members as being an effect of physical distance, in virtual groups that relationship is muddied a bit. For example, in MMOG groups, although group members may be geographically separated by thousands of miles, group members can still see the avatars of others in the environment, allowing for some visibility of others despite physical location. 
However, many of the effects of reduced visibility of others are actually about the visibility of others' behaviors, not the people themselves, although these would have been intertwined in the settings that Kahn et al. (1964) observed. Reduced visibility of the actions of fellow group members can affect the role episode process in several ways. First, in terms of the process by which role senders develop role expectations, a lack of visibility of the actions of group members can potentially have negative effects as role senders are unable to gather sufficient information about the tasks that a focal person has done or is doing in order to determine what his role should be in addition to how well he is performing that role, which can lead to unclearly developed role expectations. In contrast, when the actions of others are clearly visible, role senders can observe the focal person and gather lots of information to develop a role expectation. Second, if a focal person receives ambiguous role expectations (either as a result of unclearly defined role expectations or problems in the transmission of these role expectations), they are limited in their ability to resolve that ambiguity because they are unable to observe the actions of others and overhear the conversations of others in order to gather information about what tasks they should be doing (discussed in further detail below). As a result, the role episode process may unfold differently when group members' actions are invisible to others, as group members are unable to observe these actions to make assessments about what other people are or should be doing as well as what they should be doing, they may communicate about role expectations differently, and the consequences of role ambiguity may change when group members are not in the same space.

Research that explored role ambiguity in traditional collocated groups has identified ways in which group members can resolve ambiguous role expectations, but often these strategies require group members' actions to be visible to others (e.g., observation of others' activities in 
the environment, overhearing conversations between others) (Bechky, 2006; Kahn et al., 1964). When group members are unable to view the actions of others, they must either rely on tools to provide this information, gather this information through direct communication, or make do without the information. Exploring how various configurations of awareness displays can help reduce role ambiguity in distributed groups is the focus of this study.

\section{Using MMOGs to Study Role Ambiguity}

Role ambiguity can occur in virtually any situation that requires group work, and thus could be studied in a variety of environments. MMOGs are a useful environment for exploring role ambiguity because they are environments in which group members perform actions that would typically be invisible to others but can be made visible through the use of an awareness display. MMOGs are interesting environments to explore this concept because these are spaces in which collaboration frequently occurs, game-play in these spaces shares similarities with other types of work environments such as time invested (Yee, 2006a), group structure (Williams, Ducheneaut, Xiong, Zhang, Yee, and Nickell, 2006), and activity type (Yee, 2006b), and people in these spaces have some role differentiation which allows for overlap (Boudreau, 2005). 


\section{CHAPTER 4}

\section{MMOGS}

\section{What are MMOGs?}

In MMOGs, players use the Internet to connect to a fantasy environment (e.g., a medieval or outer space setting), in which they can form groups and play with friends and strangers from around the world (Nardi and Harris, 2006). Players typically create avatars as a visual representation of a player in the game's environment, although the avatar's appearance need not resemble the player (for instance, a player may choose an avatar which looks like an elf or a troll). One goal in these games is to advance one's avatar, which is done through activities such as killing monsters or completing game objectives; the strength of the monsters and the difficulty of the game objectives increase as players progress through the game (e.g., Ducheneaut et al., 2006).

When a player creates an avatar, in addition to selecting the physical characteristics of these avatars, players also choose which class they will play. Each MMOG has a range of classes (often 8-12) with a variety of names, but the main role of each class can be boiled down to one of three primary functions. Damage Takers bear the brunt of damage inflicted by enemy monsters, but have less powerful offensive attacks and cannot repair damage that has occurred to themselves or others. Damage Dealers have the most powerful offensive attacks, but cannot withstand having much damage inflicted on them by enemy monsters, and cannot repair damage that has occurred to themselves or others. Healers can repair damage that has occurred to themselves or others, but have limited offensive capabilities and cannot withstand much direct 
damage. These classes are intended to be complementary, and have been designed to be most functional when players form groups with players from different class types (Boudreau, 2005).

\section{Collaboration in MMOGs}

As players progress through the game and are faced with increasingly challenging content, the amount of time that players spend grouped with others increases. As players reach the highest levels in the game, they spend approximately half of their time in parties with other players (Ducheneaut et al., 2006). Furthermore, players who spend more of their play time in groups with other players progress through the game more quickly, which reinforces the idea that collaborating with other players is more efficient than attempting activities alone. These parties are temporary by design and typically last for only the duration of the task, which can range from approximately 30 minutes to 6 hours in the case of the game EverQuest (Boudreau, 2006).

While in these groups, players can complete a variety of collaborative tasks, including gathering in-game resources or completing objectives (Boudreau, 2005), or competing against other players in games such as capture the flag (Nardi and Harris, 2006). However, the most interdependent and collaborative activity in these games are called dungeons. Dungeons are activities that require real-time, complex group activity (Bardzell et al., 2012). Players complete dungeons in groups of 5,10, or 25 (at one time, up to 40 players completed a dungeon together); 10 player or larger groups are typically called raids. These activities take place in areas that are separated from the rest of the virtual world (called "instances"), which prevents interference from players who are not part of the dungeon group. There are a number of different dungeons, but any given dungeon is virtually identical in terms of the environment and enemy encounters each time a group enters it. The dungeon itself is similar to a virtual obstacle course, in which players progress along a set path, killing powerful enemies along the way. The primary incentive 
to participating in a dungeon group is the rewards, as the most powerful and desirable items are only attainable by defeating specific dungeon enemies.

\section{Role Differentiation and Ambiguity in MMOGs}

As highlighted in the above sections, players in MMOGs spend a significant portion of their play time participating in a variety of collaborative activities with other players, such as the dungeons described above. Each avatar is also of a given class (which is selected when a player first creates an avatar), which governs the skills and abilities that an avatar can perform.

Each avatar class has a uniquely combined set of skills, such that no two classes have the exact same skill combinations. This creates some role differentiation on a large scale, but there are many areas of overlap that may create instances of role ambiguity when players form groups. For example, in the game World of Warcraft, there are at least six classes (mage, warlock, rogue, hunter, priest and shaman) that can temporarily incapacitate an enemy, rendering it unable to attack the group. When only one of these six classes are in a party, then the player with the avatar of one of those classes knows that he or she is responsible for performing that duty during the dungeon, as no other players are capable of doing so. However, if more than one of these classes is in a party, those players must determine who is responsible for this task at any given time, which may lead to confusion about what one should be doing. If confusion does occur, it may have negative consequences on performance (e.g., tasks not being completed because players assume that others will undertake those activities.)

Some past research on MMOGs has touched on aspects of role ambiguity among player groups, although it was not described as such. Role ambiguity was experienced by players both in terms of being unsure of the roles of themselves as well as others in the group (Chen, 2009) and in terms of being unsure how their role performance would be evaluated (Bardzell et al., 
2008). These two types of ambiguity are very similar to two of the four key types of role ambiguity in organizations that was described by Kahn et al. (1964), in terms of being unsure of the scopes of responsibility for themselves and others, as well as uncertainty about the way in which one's supervisor evaluates the adequacy of one's work. In MMOGs there are no supervisors for players to be concerned about, but players reported being concerned and confused about how other group members will evaluate the adequacy of their work.

As a result, this presents an opportunity to explore role ambiguity in MMOG groups. First, the lack of visibility of the actions of others will likely impact the role episode process for members of MMOG groups. For example, being unable to see others can impact the role episode process because it can lead to unclearly defined role expectations, and it can also limit the ways in which focal people can take action to reduce the role ambiguity they experience (e.g., by drawing inferences about their role by observing or overhearing others). Therefore, there is an opportunity to investigate how the role episode model unfolds in MMOG groups and to determine whether the process is disrupted because group members cannot see the actions of others, or do they make adjustments in order to facilitate the process (e.g., utilizing tools to gather information about a focal person). Second, this presents an opportunity to more deeply explore communication about roles among members of MMOGs groups (for example, do group members talk more about their and others' roles since they are unable to see what others are doing, and develop ways that this type of communication can be promoted within these and other, similar types of groups.

Awareness Displays in MMOGs

As mentioned above, group members in MMOG groups are sometimes unable to see the actions of other group members while completing group activities. Being able to see the actions 
of others is important for both the development of role expectations as well as the strategies that a focal person can utilize to determine his role under ambiguous circumstances. However, in MMOGs, otherwise invisible behaviors can be made visible through the use of awareness displays. For example, while players' avatars display animations which correspond with various actions (e.g., spell casting, archery), there are often numerous actions which share the same animation, which can lead to ambiguity surrounding which action the player is actually performing. Awareness displays can provide visual information about what actions are actually being performed. Therefore, visual awareness displays are one type of tool that technological systems can employ to help reduce role ambiguity in MMOG groups.

These displays provide players with information that could be used to help role senders develop more clearly defined role expectations about a focal person. Furthermore, in the event that a focal person does not receive clearly defined role expectations from role senders (either because the role senders did not make a clearly defined role expectation with the information provided, or a clearly defined role expectation was transmitted in a way that created ambiguity), he can draw on information provided by the displays to engage in strategies such as observing the actions of others or overhearing task-related communication which are helpful in reducing role ambiguity (Kahn et al. 1964; Bechky, 2006). If the awareness displays did not make these invisible actions visible, in some cases players would be able to gather information about these actions in the game environment (with varying degrees of detail and accuracy), and in other cases individuals would not have access to this information at all unless it was explicitly communicated between group members. While the player groups observed by Chen (2009) and Bardzell et al. (2008) had methods for explicitly communicating role expectations for dungeon 
and raid group members, there were times in which this process either was ineffective or broke down completely, leading to role ambiguity among the group members.

There are a number of different types of information to players that can be useful in forming role expectations about focal people or helping focal people clarify their role in an ambiguous situation. First, these displays provide basic information about others in the group (which, for the given task, would be the role set) such as players' names, classes, levels, and whether they are currently online. This is one of the fundamental traits of awareness (Schmidt, 2002), and is useful for engaging in the role episode model because it would be very hard to develop role expectations regarding one's actions if role senders do not have a basic sense of who others are, and for a focal person trying to reduce role ambiguity, it is useful to have a sense of what others in the role set may or may not be capable of doing. Without an awareness display, information about players' names could only be gathered through direct communication, information about players' classes and levels could be only roughly estimated by observing their character in the environment (e.g., the type of armor that a player wears gives some hints about his class and level, but this information would not be very accurate), and online status can be inferred with a delay depending on whether the avatar is still in the game space. Additionally, as mentioned above, awareness displays provide information about the virtual actions of others, as well as whether they are under the effects of spells that can beneficially or detrimentally affect their virtual actions (e.g., there are spells which prohibit a player from moving or casting any spells for a set amount of time). Making otherwise invisible virtual actions visible is useful for engaging in the role episode model because it illustrates what others are doing, and whether their virtual actions are limited by factors outside their control. Without this display, individuals would only be able to gather information about spell effects through direct communication, and 
could only gather a rough estimate of current virtual action by observing players in the game environment (e.g., a role sender could determine that a focal person is casting spells versus resting, but may not be able to determine which spells she is casting).

Exploring the use of awareness displays among MMOG groups in this ways allows for a deeper understanding both of how role ambiguity can be reduced by making otherwise invisible behaviors visible as well as investigates how awareness displays can be used for more than status updates and real-time coordination assistance.

In terms of how awareness displays can help reduce role ambiguity by making the behaviors of others easily visible, there is also value in considering how the configuration of the display can affect how this occurs. As mentioned earlier, one way in which awareness display types can differ is based on the amount of shared information it provides versus tailoring information for individuals (e.g., Zhu, 2004). The standard awareness display included in most, if not all, MMOGs is one that is identical for each group member, regardless of their role. However, alternate configurations could be imagined in which the awareness display is tailored according to player type (i.e., damage takers, damage dealers, and healers).

To reduce role ambiguity, an awareness display should make others' actions visible so that role senders can develop (and transmit) clear role expectations for others and so that focal people can use that information to make inferences about what tasks they should be performing when role expectations are not clearly transmitted. A tailored awareness display can improve on this by emphasizing or de-emphasizing certain information to help these steps occur quickly and without being cognitively demanding.

One way that making actions visible can help reduce role ambiguity in MMOG groups is by providing role senders with the information they need to develop clear role expectations about 
focal people. This suggests that some degree of information about all group members' actions should be provided to everyone. However, too much detail about the activities of others may be cognitively demanding (Dabbish and Kraut, 2004), and may require a lot of effort to develop clear role expectations for others. An alternative configuration could abstract information about actions of group members who perform activities that are less affiliated with the person viewing the display (e.g., a damage dealer could view abstracted information about the actions of a healer), so that he can receive enough information to form a role expectation for that focal person without spending too much effort doing so. For example, in the case of a damage dealer receiving information about the actions of a healer, an awareness display could provide flashes of colors when a group member is taking damage or being healed, instead of displaying health bars that rise and fall when these actions are taken. This allows the damage dealer to develop a clear role expectation about the healer without having to spend the effort to closely monitor others' health bars, which is a task a damage dealer does not normally have to do.

A tailored awareness display could also help when a focal person is viewing the actions of others to get a sense of what he should be doing in a situation where role ambiguity has already occurred. While a focal person can view the actions of all other group members to determine what is or is not being done, he will not be able to perform every possible task that can further help the group complete its activity (e.g., a damage dealer is incapable of healing others, even if the healer is failing at doing so). A tailored display could help emphasize the tasks that the person viewing the display is able to do. For example, the popular World of Warcraft addon CT Raid Assist (www.ctmod.net) flashes a text warning when a buff that the user can cast has faded off of another group member. This idea could be used with other tasks to emphasize the ways in which that person can contribute toward the group's success. This study will explore 
how tailored awareness displays can contribute toward group success by reducing role ambiguity in distributed MMOG groups. 


\section{CHAPTER 5}

\section{HYPOTHESES}

This study explores the role of awareness displays for making otherwise invisible behaviors visible to aid in information gathering by both role senders and focal people to reduce role ambiguity in collaborative MMOG groups using an experimental research design. In MMOGs, like in many online environments, many actions that group members take are not visible to others. For example, while others can see that an avatar is shooting a crossbow, there are a number of different attack actions that would yield such an animation, and therefore it is unclear which action is actually being performed. Visual awareness displays are a way to make those invisible underlying behaviors (the behavior actually being performed), and allow individuals to engage in information gathering behaviors, either for role senders to develop clearly defined role expectations about focal people, or for focal people to take steps to reduce existing role ambiguities using strategies similar to the ones described by (Bechky, 2006 and Kahn et al., 1964).

Furthermore, the type of awareness display used may impact how group members gather relevant information about their roles in the group. This study will compare two standard awareness displays and a tailored awareness display in terms of their effects on role ambiguity in MMOG groups. Typically, awareness displays are shared such that each group member sees the same information, regardless of their role in the group. However, there is an alternative to this type of display, which allows information to be tailored to individuals (Zhu, 2004). Tailoring an 
awareness display for individuals may help reduce role ambiguity in two ways. First, tailoring displays to de-emphasize (although not eliminate) information about the actions of others that are less related to the person viewing the display (e.g., abstracting information about healing for a damage dealer) will allow that role sender to less effortlessly develop clear role expectations about the appropriate focal person. Second, tailoring displays to emphasize tasks that the person viewing the display can perform can help him take steps to reduce role ambiguity that has already occurred by indicating possible tasks that he can undertake to help the group complete their activity. A display that was tailored to the individual such that it emphasized the information most relevant to their ideal role and minimized other information may be most useful for reducing role ambiguity in an otherwise ambiguous situation, as opposed to shared displays that either abstracted or detailed all role information. Therefore, I hypothesize that:

H1: Participants in groups using tailored visual awareness displays will report less role ambiguity at the completion of the task than participants in groups using either abstract or detailed visual awareness displays.

Additionally, the type of display presented to the group may impact how quickly group members gather and absorb relevant role information, which would affect the degree of role ambiguity during the task. A tailored awareness display, which emphasizes the information that is most relevant to each person, may provide individuals with relevant information quicker than either of the shared display types. Therefore, I predict that:

H2: Participants in groups using tailored visual awareness displays will report less role ambiguity during the task than participants in groups using either abstract or detailed visual awareness displays. 
Traditionally, visual awareness displays have been used as tools to provide updates about the status of collaborators to assist with real-time coordination. However, as described above, a WYSINWIS-style display that is tailored to one's abilities and skills also has the potential to help group members learn their role in the group, and apply that knowledge to future group work. If this is true, it should mean that group members become increasingly clear about their roles over the course of the group activity when exposed to a role-tailored display, which should have a positive impact on their performance in two ways. First, these groups should display greater evidence of learning as demonstrated by improvement on the task over time. Second, these groups should perform better overall than groups without access to a tailored display as they benefit from this extra knowledge. Additionally, having a clearer understanding of one's role within a group should not only lead to reduced role ambiguity, but a more positive experience with the task itself as well as more positive attitudes toward one's fellow group members. Therefore, I hypothesize that:

H3: Participants in groups using tailored awareness displays will perform better on the task than participants in groups using either abstract or detailed awareness displays.

H4: Participants in groups using tailored awareness displays will increase their performance more over the course of the task than participants in groups using either abstract or detailed awareness displays.

H5: Participants in groups using tailored awareness displays will have greater task satisfaction following the task than participants in groups using either abstract or detailed awareness displays. 
H6: Participants in groups using tailored awareness displays will have greater social satisfaction following the task than participants in groups using either abstract or detailed awareness displays.

In addition to the effects hypothesized above, the type of awareness display that is available may impact how the role episode process occurs in MMOG groups. First, one of the advantages of having awareness in collaboration is that reduces conversation and makes communication more efficient (Gutwin and Greenberg, 2002), which can assist with conversational grounding (Clark and Brennan, 1991.) Therefore, when an awareness display provides relevant information to group members, they should be able to see the information that they ordinarily would have talked about, and can instead focus their communication on other issues. However, explicit verbal communication is an important part of information sharing in collocated groups (Hutchins, 1990; Heath and Luff, 1995), even when there are many environmental cues available. Conversation is also an important strategy for identifying one's role in a collocated group (Bechky, 2006), even though there is much more information visible to group members when groups are collocated. Therefore, even if information about activities is available through an awareness display, people will likely still talk about their roles and transmit role expectations. However, the way they talk about their roles may change. Without appropriate awareness information, both role senders and focal people may be confused about the current state of the environment (Endsley, 1995), so there should be more questions about roles and explicit communication about the activities for which certain focal people are responsible. With appropriate awareness information, these same people may still talk about roles, but differently (e.g., sharing tips on how to perform roles, complaining about challenges of executing roles), 
mirroring the type of face-to-face communication seen in collocated groups (Kahn et al. 1964; Bechky, 2006). Therefore, I present the following hypotheses:

H7: Participants in groups using a tailored awareness display will make fewer statements about roles than participants in groups using either an abstract or detailed awareness display.

H8: Participants in groups using a tailored awareness display will make fewer explicit statements reflecting role ambiguity than participants in groups using either an abstract or detailed awareness display.

H9: Participants in groups using a tailored awareness display will ask fewer questions about roles and role directions than participants in groups using either an abstract or detailed awareness display. 


\section{CHAPTER 6}

\section{METHOD}

\section{Participants}

One hundred ninety-two participants were recruited to complete a collaborative online video game task, using the game "Neverwinter Nights." All participants were students or staff at a large US university. Participants were recruited via an on-campus web-based recruitment system, and received either $\$ 10$ cash or course credit for their participation. Participants signed up for the experiment individually, and were formed into groups at the time of the experiment. Two groups were excluded from analysis due to technical problems during the experiment; the final sample included 186 participants. Participants ranged from 18 to 34 years of age $(\mathrm{M}=20$ years), and $94(50.5 \%)$ were female. In recruiting materials, it was indicated that participants should have experience and familiarity with playing video games, so that they would have at least basic proficiency with performing the experimental task after completing a tutorial (e.g., would be able to move their avatar within the game environment.) One hundred seventy-three participants $(93.0 \%)$ had played either a console or PC based video game for at least one session lasting longer than an hour in the last five years. In the week prior to participating in the study, $27 \%$ of participants had played console based video games, for an average of 1.31 hours $(\mathrm{SD}=$ 3.79 hours). $34 \%$ of participants had played PC based video games for an average of 2.75 hours $(\mathrm{SD}=5.65$ hours). Only two participants had played Neverwinter Nights or Neverwinter Nights 2 prior to taking part in the study. 


\section{Game Environment}

This experiment required participants to work in groups while completing a task in a custom module in Neverwinter Nights, which is an online fantasy role-playing game, in which players can form groups with others and undertake a variety of activities, such as completing game objectives and killing enemy monsters. This game has an advantageous feature in terms of building an experiment, in that it allows for the custom creation of unique game modules, in which many aspects of game play, such as avatar traits, the user interface, and the game environment can be configured or modified using the Aurora toolset. These modules can be stored on a local server and played by a closed group of individuals. In contrast to other similar MMOGs, which place strict limits on the modifications allowed or user control of game modules, this allowed for the maintenance of experimental control and limited potential threats to the internal validity of an experiment such as the presence of others, changes in content, or participants' prior experience with the task. All modules used for the experiment were stored on laboratory computers and accessible only to participants for the duration of the experiment.

During the task, participants were able to communicate with each other via chat by typing into a text box that was integrated into the game. The text box displayed up to four lines of text before being bumped out of view, although participants could scroll up to review past messages. There was no decay rate, so messages would persist in the text box until they were bumped out of view.

Task

Three-person groups were asked to perform a fifteen-minute task in the video game Neverwinter Nights, which was adapted from a previous study examining collaboration in an online video game environment (Reynolds, Birnholtz, and Lee, 2012). Players were instructed to 
travel along a designated path and kill the enemy goblins they encountered during the fifteen minutes. To reduce the possibility of a ceiling effect on this aspect of the task, it was designed such that no group would be able to kill all the goblins in the allotted time. In addition, the enemies were also able to attack the players, so participants were instructed to avoid being killed by the goblins. To encourage collaboration, the enemy goblins were designed to be so difficult to kill that no single player could successfully kill a goblin without dying first. Dying was not permanent; participants were presented with the ability to "respawn" after dying and return to the game. However, respawning came at a cost to players, as there was a fifteen second delay between using the respawn ability and rejoining the game. As the time needed to kill the goblins is fairly short (approximately thirty to forty five seconds), this delay created an incentive for players to avoid being killed by the goblins. Players were also incentivized to collaborate on the task through a point system in which each time a goblin was killed, the group earned ten points, but each time one of the participants' avatars died, their group lost three points.

\section{Roles}

Each player was randomly assigned a unique role, with two role-specific abilities as well as avatar traits that were designed to be interdependent in that there would be a natural division of labor among the participants. Participants were not explicitly told what their role was, although the names of their abilities were provided along with how to use each of the abilities (e.g., press F2 to cast "cure minor wounds"). Participants were also not told anything about the roles or abilities of the other participants in their group. In addition to the two role-specific abilities, each player had an ability that equipped their weapon, a basic weapon attack ability, and a shared ability called "detect mode" that was designed as to neither help nor hurt player performance regardless of their individual role. 
Roles were as follows:

Barbarian (Damage Dealer): The barbarian was optimized to deal damage to the goblins, as it was provided with a hand axe to use to kill goblins, and had a maximum of 14 health points. Initial health point level is a measure of how much damage a player can withstand before dying or having their health restored. The role-specific abilities for the barbarian were "Barbarian Rage," which increased the damage dealt by weapon attacks during the next fight by $10 \%$, and "Power Attack," which was an especially powerful attack that could be used in conjunction with weapon attacks.

Monk (Damage Taker): The monk was optimized for defensive abilities, including being able to withstand the most damage from goblins. The monk had a maximum of 19 health points, meaning they could take more damage from the goblins without dying or having their health restored. The role-specific abilities for the monk were "Parry," which blocked a goblin's next attack on the monk so that it did not deal damage, and "Taunt," which redirected a goblin's focus and attacks away from its current target (assuming its current target was not the monk) and onto the monk (e.g., if the goblin was attacking the barbarian when the monk used its' taunt ability, the goblin would stop attacking the barbarian and begin attacking the monk instead.)

Cleric (Healer): The cleric was optimized to restore health to players after they had taken damage from goblin attacks. The cleric had a maximum of 10 health points, and as such could withstand only a small amount of damage from the goblins. The cleric was able to use spells to restore the health of any player, including herself. The role specific abilities for the cleric were "Cure minor wounds" and "Cure light wounds," both of which restored lost health points to players, although "Cure light wounds" healed more health points than "Cure minor wounds" did (14 vs. 11 health points.) 


\section{Procedure}

After receiving a brief verbal introduction to the experiment, participants were placed in separate rooms equipped with a computer and stayed there for the duration of the experiment. Once in their rooms, participants filled out a consent form, completed a demographic questionnaire that asked about their experience with various types of video games, and were presented with a sheet that explained the nature of the experimental task. They then watched a short instructional video that introduced them to game concepts (e.g., how to move their avatar and how to move the camera orientation) as well as their avatar's abilities. Following the video, participants were given a reference sheet with this material. The task introduction and reference sheets are listed in Appendices 1 and 2.

Participants then completed a three minute long practice task to familiarize themselves with the game's controls and how to use their avatar. Following this individual practice, participants completed a fifteen minute long group task. The game was paused at minutes two, five and ten, at which point participants were asked to fill out the "during task survey," that asked about the abilities of each member of the group. When all group members completed the survey, the game was unpaused and the task resumed. When the task was completed, participants completed a final "during task survey," as well as three questionnaires that asked about their feelings about the task, their role in the group, and their group members. All questionnaires are listed in Appendix 3.

\section{Experimental Conditions}

Groups were randomly assigned to complete the task described above while viewing one of three types of awareness displays. The type of awareness display (tailored, abstract, or detailed) made available to participants during the task was a between-subjects manipulation 
made at the group level. Each of the display conditions provides information about each of the three player roles, but the way that this information is presented to players is what distinguishes the three display types. Both the abstract and the detailed display types presented information uniformly to all group members regardless of role, in a WYSIWIS format. In contrast, the tailored display presents information to group members differently depending on their role, in a WYSINWIS format.

The three display types shared some common features that were not modified in any of the experimental conditions. Each display showed a large portrait of each player, smaller portraits of the other two group members, and the relative location of each group member to the person viewing the display. These displays also provided buttons for an individual to use to trigger important functions such as resting (which participants could use between fights to help them restore their health). Lastly, at the bottom of the screen there were hotkeys which triggered their general and role-specific abilities (the location of the hotkeys were not modified in any of the experimental conditions, but the colors of the keys were, as described below.)

Modifications to Neverwinter Nights' standard display were made such that information about each of the player roles could be presented in either a detailed or abstracted way. The abstract display presented abstracted information about each of the player roles, the detailed display presented detailed information about each of the roles, and the tailored display presented detailed information about one's own role and abstracted information about the other two roles. Specific information on each of the displays and the exact nature of the display modifications is detailed below.

Tailored Display: Each participant was presented with detailed information about their role and abstracted information about other group members' roles. 


\begin{tabular}{|l|l|l|l|}
\hline $\begin{array}{l}\text { Player viewing the } \\
\text { display }\end{array}$ & $\begin{array}{l}\text { Info presented about } \\
\text { the cleric }\end{array}$ & $\begin{array}{l}\text { Info presented about } \\
\text { the barbarian }\end{array}$ & $\begin{array}{l}\text { Info presented about } \\
\text { the monk }\end{array}$ \\
\hline Cleric & $\begin{array}{l}\text { Rainbow Colorized } \\
\text { Health Bars (Figure } \\
2) \\
\text { Colorized Ability } \\
\text { Icons (Figure 8) }\end{array}$ & $\begin{array}{l}\text { Damage dealt visual } \\
\text { effect (Figure 5) }\end{array}$ & $\begin{array}{l}\text { Subtle goblin target } \\
\text { visual effect (Figure } \\
7)\end{array}$ \\
\hline Barbarian & $\begin{array}{l}\text { Abstracted Health Bar } \\
\text { (Figure 3) }\end{array}$ & $\begin{array}{l}\text { Lifebar (Figure 4) } \\
\text { Colorized Ability } \\
\text { Icons (Figure 8) }\end{array}$ & $\begin{array}{l}\text { Subtle goblin target } \\
\text { visual effect (Figure } \\
7 \text { ) }\end{array}$ \\
\hline Monk & $\begin{array}{l}\text { Abstracted Health Bar } \\
\text { (Figure 3) }\end{array}$ & $\begin{array}{l}\text { Damage dealt visual } \\
\text { effect (Figure 5) }\end{array}$ & $\begin{array}{l}\text { Obvious goblin target } \\
\text { visual effect (Figure } \\
\text { 6) } \\
\text { Colorized Ability } \\
\text { Icons (Figure 8) }\end{array}$ \\
\hline
\end{tabular}

Table 1: Description of the tailored display

Abstracted Display: Each participant was presented with abstract information about all three player roles.

\begin{tabular}{|l|l|l|l|}
\hline $\begin{array}{l}\text { Player viewing the } \\
\text { display }\end{array}$ & $\begin{array}{l}\text { Info presented about } \\
\text { the cleric }\end{array}$ & $\begin{array}{l}\text { Info presented about } \\
\text { the barbarian }\end{array}$ & $\begin{array}{l}\text { Info presented about } \\
\text { the monk }\end{array}$ \\
\hline Cleric & $\begin{array}{l}\text { Abstracted Health Bar } \\
\text { (Figure 3) }\end{array}$ & $\begin{array}{l}\text { Damage dealt visual } \\
\text { effect (Figure 5) }\end{array}$ & $\begin{array}{l}\text { Subtle goblin target } \\
\text { visual effect (Figure 7) }\end{array}$ \\
\hline Barbarian & $\begin{array}{l}\text { Abstracted Health Bar } \\
\text { (Figure 3) }\end{array}$ & $\begin{array}{l}\text { Damage dealt visual } \\
\text { effect (Figure 5) }\end{array}$ & $\begin{array}{l}\text { Subtle goblin target } \\
\text { visual effect (Figure 7) }\end{array}$ \\
\hline Monk & $\begin{array}{l}\text { Abstracted Health Bar } \\
\text { (Figure 3) }\end{array}$ & $\begin{array}{l}\text { Damage dealt visual } \\
\text { effect (Figure 5) }\end{array}$ & $\begin{array}{l}\text { Subtle goblin target } \\
\text { visual effect (Figure 7) }\end{array}$ \\
\hline
\end{tabular}

Table 2: Description of the abstract display

Detailed Display: Each participant was presented with detailed information about all three player roles.

\begin{tabular}{|l|l|l|l|}
\hline $\begin{array}{l}\text { Player viewing the } \\
\text { display }\end{array}$ & $\begin{array}{l}\text { Info presented about } \\
\text { the cleric }\end{array}$ & $\begin{array}{l}\text { Info presented about } \\
\text { the barbarian }\end{array}$ & $\begin{array}{l}\text { Info presented about } \\
\text { the monk }\end{array}$ \\
\hline Cleric & $\begin{array}{l}\text { Rainbow Colorized } \\
\text { Health Bars (Figure } \\
\text { 2) and Colorized } \\
\text { Ability Icons (Figure }\end{array}$ & Lifebar (Figure 4) & $\begin{array}{l}\text { Obvious goblin target } \\
\text { visual effect (Figure 6) }\end{array}$ \\
\hline
\end{tabular}




\begin{tabular}{|l|l|l|l|}
\hline & $8)$ & & \\
\hline Barbarian & $\begin{array}{l}\text { Rainbow Colorized } \\
\text { Health Bars (Figure } \\
\text { 2) }\end{array}$ & $\begin{array}{l}\text { Lifebar (Figure 4) and } \\
\text { Colorized Ability } \\
\text { Icons (Figure 8) }\end{array}$ & $\begin{array}{l}\text { Obvious goblin target } \\
\text { visual effect (Figure 6) }\end{array}$ \\
\hline Monk & $\begin{array}{l}\text { Rainbow Colorized } \\
\text { Health Bars (Figure } \\
\text { 2) }\end{array}$ & Lifebar (Figure 4) & $\begin{array}{l}\text { Obvious goblin target } \\
\text { visual effect (Figure 6) } \\
\text { and Colorized Ability } \\
\text { Icons (Figure 8) }\end{array}$ \\
\hline
\end{tabular}

Table 3: Description of the detailed display

In Figure 2, the Rainbow Colorized Health Bar, this modification to the standard health display provided detailed information about players' health status at a glance and is a highly rated modification currently used by Neverwinter Nights players (http://nwvault.ign.com/View.php?view=other.Detail\&id=1236). The health bar was a solid green color, and the background behind the bar was a gradient that ranges from green to dark red. Thus, participants could glance at the health bars and tell by the lowest color exposed how much health a given player had remaining, which provided helpful information for the cleric to perform her duties of healing everyone, and provided a detailed picture for the monk and barbarian to identify whether the cleric was performing her duties.

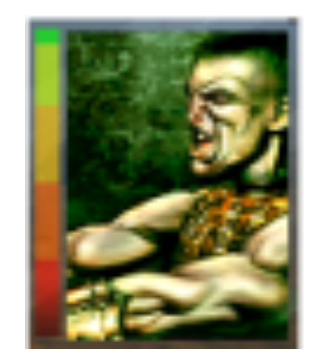

Figure 2: Rainbow Colorized Health Bar

In Figure 3, the Abstracted Health Bar, instead of the detailed colorized health bar described above, this health bar was modified to abstract information about players' health statuses. Until a player had only $50 \%$ of their health remaining, the bar did not appear to change 
color, since the health bar and background colors are the same. At that point, it began to show red colors that indicate that the player is at low health. Thus, participants had abstract information about whether any given player's health is low, which provided some information to the cleric about which players needed healing, and provided basic information to the monk and barbarian about whether the cleric was performing her duties.

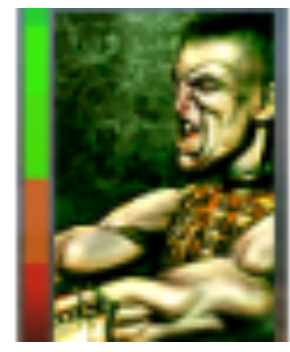

Figure 3: Abstracted Health Bar

For Figure 4, Lifebar. The modification to the display provided detailed information about enemy goblins' health. The Lifebar displayed an enemy goblin's current health level with a series of bars (up to 20) that floated above its head and appeared as soon as the goblin began attacking a player. As the goblin took damage and lost health, the number of bars decreased. Additionally, the colors of the bars changed as the goblin took damage, ranging from green at high health, yellow at middle health, and red at low health. This provided detailed information to the barbarian about the status of the goblins he was trying to kill, and provided the cleric and monk with information about whether the barbarian was successfully killing the goblin. 


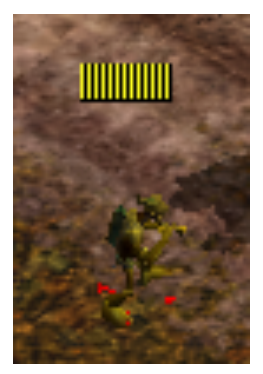

Figure 4: Lifebar

For Figure 5, the damage dealt visual effect, the modification was a visual effect that appeared when the barbarian dealt damage to the enemy, in the form of a flash of light that appeared under his avatar. This provided abstract information for the barbarian about the health of goblins as it showed that damage was dealt to the goblin, but provided no way of knowing how much health remained. It also provided information to the cleric and monk about whether the barbarian was performing his duties.

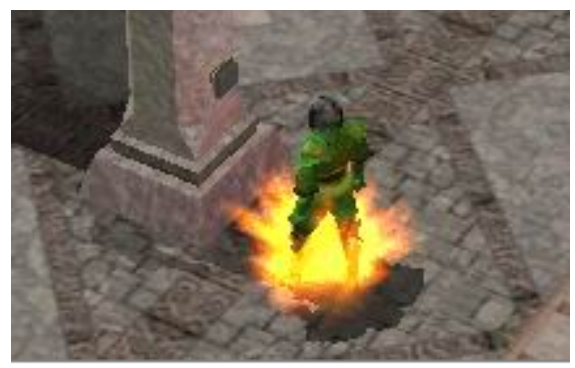

Figure 5: Damage dealt visual effect

For Figure 6, the obvious goblin target visual effect, the modification was a visual effect that clearly illustrated which player was currently the target of attacks by the enemy goblin. As the goblin attacked a player, the visual effect triggered a large white ring and "halo" to appear around them, and when the goblin switched its focus for attacks, the visual effects switched to the other player as well. This provided information to the monk about whether he was the focus 
of the goblin attacks, as well as indicates to the barbarian and cleric whether the monk was performing his duties.

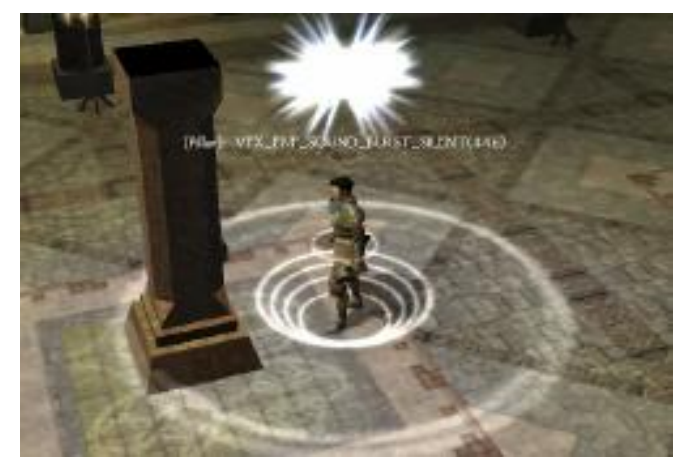

Figure 6: Obvious goblin target visual effect

For Figure 7, the subtle goblin target visual effect, the modification was a visual effect similar to the one above in that it showed which player the enemy was currently attacking, but the effect was much more subtle than above. When a goblin began attacking a player, the visual effect flashed a small white circle around the target's head. This provided information to the monk about whether he was the focus of the goblin attacks, as well as indicated to the barbarian and cleric whether the monk was performing his duties.

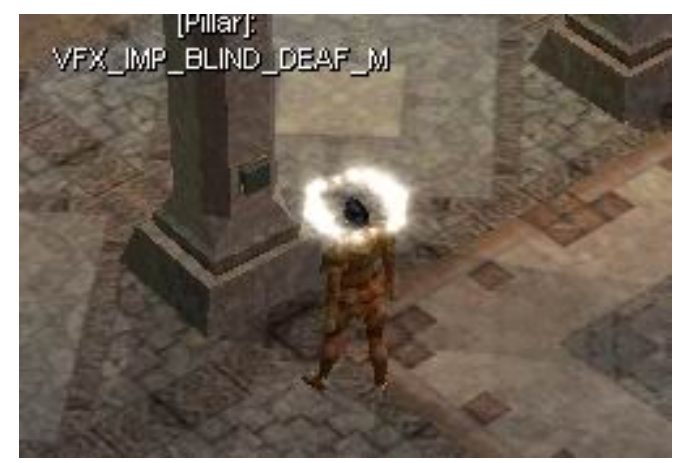

Figure 7: Subtle goblin target effect

In terms of Figure 8, the Colorized Ability Icons, on the hotkey bar at the bottom of the screen, each participant had five abilities to use. Three of these abilities were the same for all 
three group members - one which equipped their weapon, one which was a basic weapon attack, and "detect mode," which had no effect in the game (this effect allowed players to see enemies that were in stealth mode, but as none of the goblins were ever in stealth mode, using this ability had no impact.) Two of the abilities were role-specific, with the barbarian having damage dealing abilities, the cleric having healing abilities, and the monk having defensive damage taking abilities. In the tailored display condition, the icons for each player's role-specific abilities were colorized in order to have them stand out as compared with the shared abilities. This was to call attention and focus to these abilities over others.

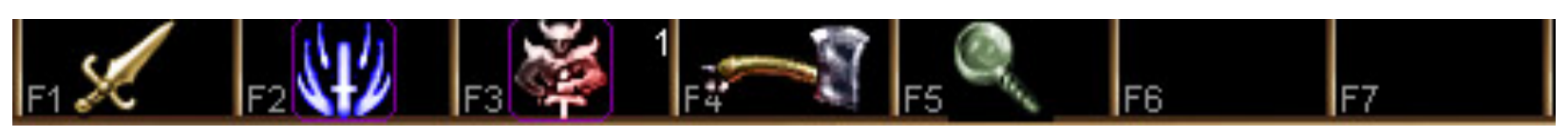

In the detailed condition, the icons for all five abilities were colorized.

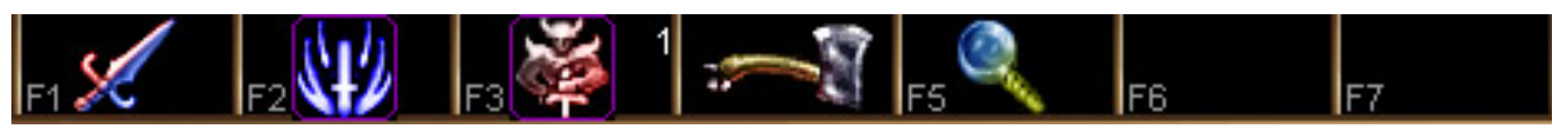

Figure 8: Colorized ability icons for the tailored and detailed conditions

Data Collection and Analysis

Performance

Neverwinter Nights allows for the automatic generation of each game session's time stamped activity log, which includes all actions performed by all players and enemies (e.g., attacks, heals) goblin kills, player deaths, pauses and unpauses, and any communication between players. The raw logs were parsed into separate files for goblin kills, player deaths, and communication. Task performance in terms of goblin kills and player deaths was calculated overall as well as for each time segment. 


\section{Questionnaires}

Role ambiguity was measured using the Role Ambiguity Scale (Rizzo, House, and Lirtzman, 1970), with 14 items (Cronbach's $\alpha=.82$ ). The scores of the items were averaged to yield a composite score. Additionally, perceptions about which group members were responsible for specific parts of the task were measured using the "during task survey" administered four times over the course of the experiment. No Cronbach's alpha was calculated for this questionnaire because the questions were not designed to measure the same concept. Task load was measured using the NASA Task Load Index (Hart and Staveland, 1988), with five items (Cronbach's $\alpha=.66$ ). Social satisfaction was measured using five questions from both the social attraction (Cronbach's $\alpha=.82$ ) and task attraction (Cronbach's $\alpha=.85$ ) subsets of the Interpersonal Attraction Scale (McCroskey, Hamilton, and Weiner, 1974). The scores of the five items from each subset were averaged to yield two composite scores for each of the roles.

\section{Transcripts}

As described above, transcripts of the communication between participants was collected by parsing the time-stamped game-generated logs, which preserved the time segments. Transcripts were coded for five main categories: role related, task related, experiment related, socio-emotional, and tangential communication. The coding scheme is detailed in Appendix 4.

Two independent coders rated $20 \%$ of the transcripts according to the guidelines detailed in the coding scheme. Agreement between the two coders was acceptable (kappa $=.83$ ), and the disagreements were reconciled through a discussion where needed. One coder then rated the remaining $80 \%$ of transcripts independently. 


\section{CHAPTER 7}

\section{RESULTS}

One consideration that impacted the analyses performed on these data was that there was a potential non-independence of performance, questionnaire, and transcript observations from participants who were in a group together. In a nested design, non-independence is the correlation between scores of participants from the same group, which means that they are more similar (or dissimilar in the case of negative correlations) than scores of participants from other groups (Kenny, 1995; Singer, 1998). This means that multilevel modeling that accounts for variability at each level of hierarchically structured data should be used (Littell, Milliken, Stroup, \& Wolfinger, 1996). Therefore, Linear Mixed Model Analysis was performed on data gathered from game logs, questionnaires, and transcripts, with responses nested within participants (when there was more than one response per participant) nested within groups. The specific details of each of the models are described below. Participant gender and total hours of video game time played in the week prior to the study were controlled for in all models, and unless noted below there were no effects of either of these variables. Note that the denominator degrees of freedom in these models are estimated using a Satterthwaite's approximation, which can yield non-integer degrees of freedom (SPSS Technical Report).

\section{Role Ambiguity}

H1 predicted that participants in groups who had access to the tailored awareness display would report less role ambiguity following the task than participants in groups who had access to either the abstract or detailed awareness displays, as tailored displays would supply the best mix 
of detail and abstraction to help individuals understand their role in the group. Three indicators of role ambiguity were used: the composite score of the magnitude of participants' role assessments in the post-task version of the "during task survey", the percentage of correct responses by participants in the post-task version of the "during task survey", and the composite score of the responses to the post-task Role Ambiguity Scale (Rizzo, House, and Lirtzman, 1970).

To test this hypothesis, three linear mixed models were created that tested: 1) the percent of correct responses on the "during task survey" taken following the task, 2) the average magnitude of responses on the "during task survey" taken following the task, and 3) the average score of responses on the Role Ambiguity Scale as dependent variables. In each model, awareness display type, player role, gender, total hours of video games played in the last week, the interaction between player role and awareness display type and the interaction between total hours of video games played in the last week and awareness display type were set as fixed variables. Additionally, the linear mixed models used for the two measures captured using the "during task survey" also included the group member that participants were responding about, whether participants were rating their own role or other group members' roles, as well the interaction between awareness display type and response target and the interaction between awareness display type and self vs. other assessment as fixed variables. H1 was not supported, as participants using the tailored display did not perform better than participants using either the abstract or detailed display on any of the measures used.

First, the percentage of correct responses provided by participants to questions asked in the "during task survey" completed after the task were examined. Higher scores on this survey indicated a better objective understanding of what each group member was able to do during the 
task. The model suggested that there was a marginally significant main effect for awareness display type, $\mathrm{F}[2,72.74]=2.80, \mathrm{p}<.1$, trending toward participants using the detailed display having the most accurate assessments. However, post-hoc comparisons revealed no significant differences in the percentage of correct responses between participants who had access to the tailored display $(\mathrm{M}=58.7 \%, \mathrm{SE}=2.7 \%)$ and those with access to the abstract display $(\mathrm{M}=65.4 \%$, $\mathrm{SE}=2.7 \%), \mathrm{t}(64.03)=-.07, \mathrm{p}>.1$, between participants who had access to the tailored display and those with access to the detailed display $(\mathrm{M}=67.0 \%, \mathrm{SE}=2.7 \%), \mathrm{t}(62.21)=-.08, \mathrm{p}>.1$, or between participants who had access to the abstract display and those with access to the detailed display, $\mathrm{t}(64.57)=-.02, \mathrm{p}>.1$.

The model also revealed a significant main effect for the target of participants' responses, $\mathrm{F}[2,360.27]=32.17, \mathrm{p}<.001$, which indicates that the responsibilities of certain roles were easier to identify than others. Post-hoc comparisons revealed that there were significant differences in responses such that participants were less accurate when answering questions about monks $(\mathrm{M}=54.4 \%, \mathrm{SE}=2.0 \%)$ than when they were answering about barbarians $(\mathrm{M}=67.4 \%, \mathrm{SE}=1.9 \%)$, $\mathrm{t}(359.25)=-.13, \mathrm{p}<.001$. Participants were also less accurate when answering questions about monks than they were when answering questions about clerics $(\mathrm{M}=69.2 \%, \mathrm{SE}=2.0 \%)$, $\mathrm{t}(361.99)=-.15, \mathrm{p}<.001$. However, there were no significant differences in the percentage of correct responses when participants were answering about barbarians and when they were answering about clerics, $\mathrm{t}(359.60)=-.02, \mathrm{p}>.1$.

There was also a significant interaction between awareness display type and target of participants' responses, $\mathrm{F}[4,360.27]=2.61, \mathrm{p}<.05$. Post-hoc comparisons revealed that for responses about the barbarian, there were marginally significant differences in the percentage of correct responses such that participants who had access to the tailored display were less accurate 
$(\mathrm{M}=61.7 \%, \mathrm{SE}=3.4 \%)$ than whose who had access to the abstract display $(\mathrm{M}=70.3 \%, \mathrm{SE}=3.4 \%)$ (all inferential statistics are provided in the table below) as well as those who had access to the detailed display $(\mathrm{M}=70.4 \%, \mathrm{SE}=3.4 \%)$, but that there was no significant difference between those who had access to the abstract display and those who had access to the detailed display. For responses about the cleric, there was a marginally significant difference in the accuracy rate such that participants who used the abstract display were less accurate $(\mathrm{M}=65.9 \%, \mathrm{SE}=3.4 \%)$ than those who used the detailed display ( $\mathrm{M}=74.0 \%, \mathrm{SE}=3.4 \%)$, but that the differences between those who used the abstract display and those who used the tailored display ( $M=67.7 \%$, $\mathrm{SE}=3.4 \%$ ) were not significant, nor were the differences between those who used the tailored display and those who used the detailed display. For responses about monks, participants who used the tailored display were less accurate $(\mathrm{M}=46.7 \%, \mathrm{SE}=3.4 \%)$ than participants who used either the abstract display $(\mathrm{M}=59.8 \%, \mathrm{SE}=3.4 \%)$ or the detailed display $(\mathrm{M}=56.8 \%, \mathrm{SE}=3.4 \%)$, but the difference between those using the abstract display and those using the detailed display were not significant. This suggests that the awareness displays were not uniformly helpful in providing information that could be used to help determine which group members had certain characteristics. However, it does appear that the detailed display was most effective at providing the information that participants needed to correctly respond to this measure.

\begin{tabular}{|l|l|l|l|}
\hline Survey Class & Awareness Display & T-test & P-value \\
\hline Barbarian & Tailored vs. Abstract & $\mathrm{t}(140.40)=-.09$ & $\mathrm{p}<.1^{*}$ \\
\hline & Tailored vs. Detailed & $\mathrm{t}(135.86)=-.09$ & $\mathrm{p}<.1^{*}$ \\
\hline & Abstract vs. Detailed & $\mathrm{t}(140.82)=.00$ & $\mathrm{p}>.1$ \\
\hline Cleric & Tailored vs. Abstract & $\mathrm{t}(145.35)=.02$ & $\mathrm{p}>.1$ \\
\hline & Tailored vs. Detailed & $\mathrm{t}(142.21)=-.06$ & $\mathrm{p}>.1$ \\
\hline & Abstract vs. Detailed & $\mathrm{t}(146.96)=-.08$ & $\mathrm{p}<.1^{*}$ \\
\hline Monk & Tailored vs. Abstract & $\mathrm{t}(143.60)=-.13$ & $\mathrm{p}<.01^{* *}$ \\
\hline & Tailored vs. Detailed & $\mathrm{t}(141.54)=-.10$ & $\mathrm{p}<.05^{* *}$ \\
\hline & \multicolumn{2}{|c|}{46} & \\
\end{tabular}


Abstract vs. Detailed $\quad \mathrm{t}(143.68)=.03$

$\mathrm{p}>.1$

Table 4: Comparisons of the Percentage of Correct Responses on the Final "During Task

\section{Survey"}

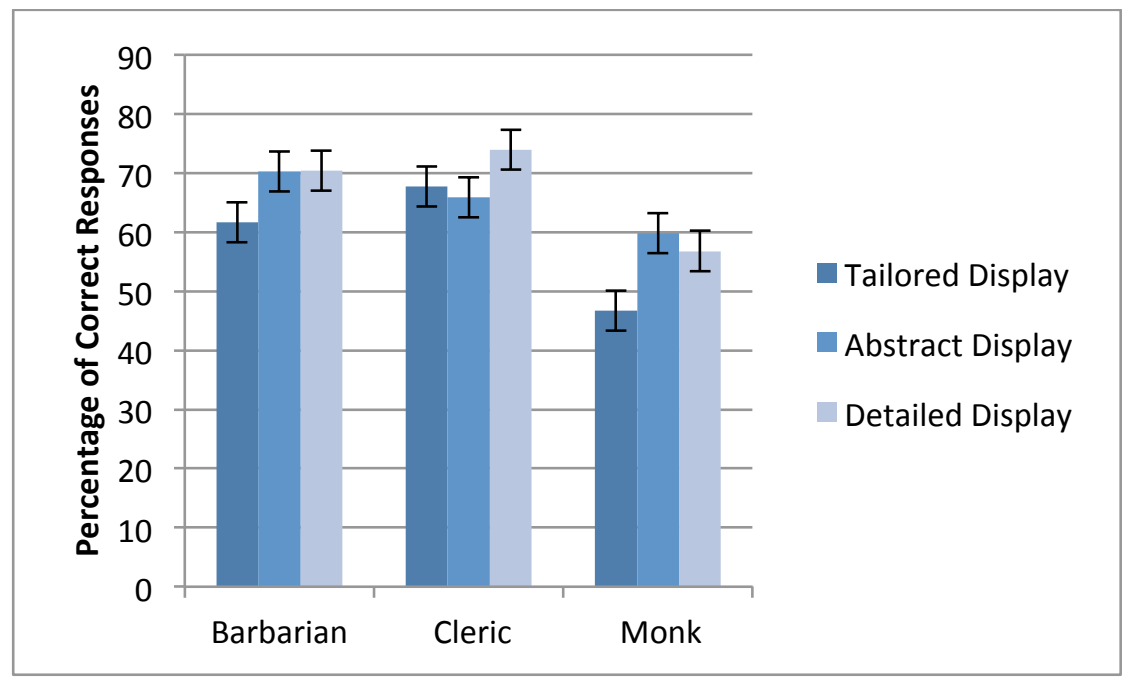

Figure 9: Percent of Correct Responses to "During Task Survey" at Completion of Task

Not surprisingly, the model also revealed that participants were more accurate about their roles in the group $(\mathrm{M}=67.8 \%, \mathrm{SE}=2.0 \%)$ than about other group members' roles $(\mathrm{M}=59.7 \%$, $\mathrm{SE}=1.7 \%), \mathrm{F}[1,367.609]=18.57, \mathrm{p}<.005$. However, there was no significant interaction between awareness display type and self vs. other assessment, $F[2,367.61]=1.20, p>.1$.

In addition to whether participants could correctly identify which aspects of the task group members were responsible for, the magnitude of their responses were also captured, and averaged to create a composite score in which higher numbers are associated with stronger opinions regarding player roles (independent of whether these opinions were correct.) In terms of the magnitude of role assessments about both made in the "during task surveys," completed after the task, there were also no significant differences in the average magnitude of responses 
whether participants had access to the tailored display $(\mathrm{M}=1.71, \mathrm{SE}=.09)$, the abstract display $(\mathrm{M}=1.81, \mathrm{SE}=.09)$ or the detailed display $(\mathrm{M}=1.88, \mathrm{SE}=.09), \mathrm{F}[2,68.80]=.70, \mathrm{p}>.1$.

The group member about which participants' were responding had a significant impact on average magnitude of response, $\mathrm{F}[2,358.67]=39.307, \mathrm{p}<.001$, which also highlights that participants developed different opinions about each of the three roles. Post-hoc comparisons revealed significant differences between all three roles, such that participants had stronger opinions on responses about barbarians $(\mathrm{M}=2.00, \mathrm{SE}=.06)$ than they did on responses to clerics $(\mathrm{M}=1.80, \mathrm{SE}=.06), \mathrm{t}(358.34)=.20, \mathrm{p}<.001$ or than they did for monks $(\mathrm{M}=1.60, \mathrm{SE}=.06)$, $\mathrm{t}(358.16)=.40, \mathrm{p}<.001$. Participants also had stronger opinions on responses about clerics than they did on responses about monks, $\mathrm{t}(359.54)=.20, \mathrm{p}<.001$. There was no significant interaction between awareness display condition and response target, however, $\mathrm{F}[4,358.68]=.82$, $\mathrm{p}>.1$. The model also indicated that one's gender significantly impacted the average magnitude of their assessments, with men having more extreme opinions $(\mathrm{M}=1.92, \mathrm{SE}=.07)$ than women did $(\mathrm{M}=1.68, \mathrm{SE}=.07), \mathrm{F}[1,168.20]=6.53, \mathrm{p}<.05$. Again, as one might expect, the model revealed that participants had stronger opinions about their role in the group $(\mathrm{M}=1.89, \mathrm{SE}=.06)$ than other group members' roles $(\mathrm{M}=1.70, \mathrm{SE}=.06), \mathrm{F}[1,358.89]=22.94, \mathrm{p}<.001$, but that there was no significant interaction between awareness display type and whether one was answering about themselves or others, $F[2,358.86]=.58, \mathrm{p}>.1$.

Lastly, participants also completed the Role Ambiguity Scale, which measures feelings of role ambiguity with regard to one's own role in the group (Rizzo, House, and Lirtzman, 1970) after the task was fully completed, and individual measure items were averaged to create a composite score. Lower scores are associated with higher levels of role ambiguity (on a sevenpoint scale, with 1 indicating much ambiguity and 7 indicating no ambiguity.) In contrast to the 
percentage of correct responses to the "during task survey," the type of awareness display did not impact participant responses on this measure, (tailored display: $M=4.04, S E=.12$, abstract display: $M=4.10, S E=.12$, detailed display: $M=4.04, S E=.12), \quad F[2,75.63]=0.02, \mathrm{p}>.1$. Participant role, however, significantly impacted role ambiguity, $3 \quad F[2,121.45]=5.87, p<.005$. Post-hoc comparisons revealed that participants playing barbarians reported significantly lower role ambiguity $(M=4.31, S E=.11)$ than participants playing monks $(M=3.84, S E=.11), \mathrm{t}=.49$, $\mathrm{p}<.005$, but that there were no significant differences in the responses of participants playing barbarians and clerics $(M=4.02, S E=.11), \mathrm{t}=.29, \mathrm{p}>.1$, and participants playing clerics and monks, $\mathrm{t}=.17, \mathrm{p}>.1$. Additionally, there was no significant interaction between participant role and awareness display type, $\mathrm{F}[4,121.96]=.275, \mathrm{p}>.1$.

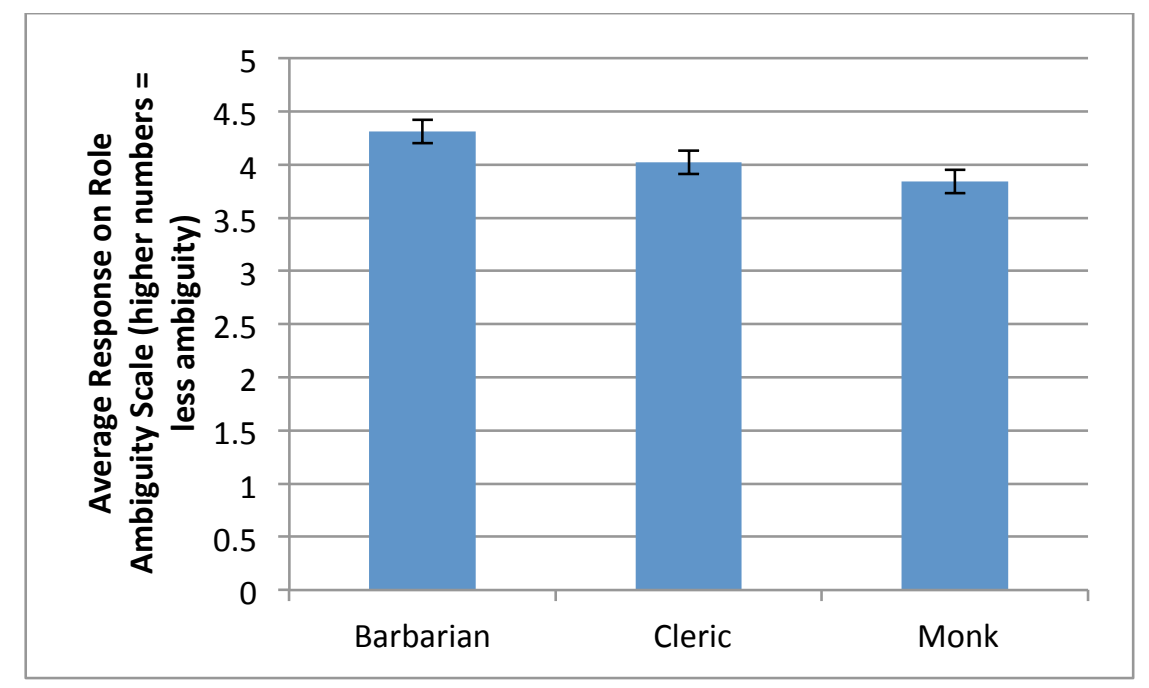

Figure 10: Average Composite Score on the Role Ambiguity Scale by Participant Role (lower scores indicate higher ambiguity)

Summarizing these findings on role ambiguity at the completion of the task, H1 was not supported, as the tailored display was not more beneficial than the other two types of displays for reducing participant role ambiguity in terms of the three indicators. The detailed display appears 
to be best overall in terms of facilitating the correct identification of group roles, but awareness display type had no impact in terms of magnitude of opinions or experiences of role ambiguity. Participants had fewer correct responses about the monk role than the other two roles, suggesting that that role was harder to identify, possibly because the defensive damage mitigating abilities of monks were less visible to participants than the offensive abilities of the barbarian or the healing abilities of the cleric.

Participants had both more correct and more extreme beliefs about their own roles than the roles of the other members of their groups but that this did not interact with awareness display condition, which indicates that the information that participants used to develop beliefs about their own roles was not part of the experimental manipulation. Specifically, participants may have come to these conclusions based on using their role-specific abilities and understanding what they were best able to do. Furthermore, while there were no differences in the accuracy or magnitude of responses to the questions asking about the objective differences between roles, there were differences to the responses about feelings and experiences of role ambiguity based on participant role type. Participants playing barbarians reported experiencing less role ambiguity than participants playing monks did. One interpretation for this is that barbarians likely had the clearest role of all three players in terms of killing the goblins. In contrast, as mentioned above the defensive role of the monk is much less obvious and tangible. Even though monks identified their role as well as barbarians by the end of the task, this difference in accessibility of role understanding can explain the difference in their subjective experiences of role ambiguity following the task.

$\mathrm{H} 2$ posited that differences in role ambiguity would be evident during the task, such that participants in groups who had access to the tailored awareness display would report less role 
ambiguity during the task than participants in groups who had access to either the abstract or detailed awareness displays. Two indicators of role ambiguity were used: the magnitude of participants' role assessments and percentage of correct responses by participants on the "during task survey" following time segments 1,2, and 3.

To test this hypothesis, eight linear mixed models were created with the following dependent variables: the percentage of correct responses on the "during task survey" following time periods, 1, 2, and 3, as well as the aggregate of the responses for those time periods, and the average magnitude of responses on the "during task survey" following time periods 1, 2, and 3, as well as the aggregate of the responses for those time periods. Each model was constructed with awareness display type, player role, response target role, gender, total hours of video games played in the last week, self vs. other assessment, the interaction between player role and awareness display type, the interaction between response target role and awareness display type, the interaction between total hours of video games played in the last week and awareness display type, and the interaction between self vs. other assessment and awareness display type set as fixed variables.

$\mathrm{H} 2$ was not supported, as there were no significant differences in any of the responses detailed below based on whether participants had access to the role tailored display, abstract display, or detailed display

First, the percentage of correct responses provided by participants to questions asked in the "during task survey" aggregated across times 1, 2, and 3 were explored. There were no significant differences in terms of the average percentage of correct responses based on whether participants had access to the tailored display ( $\mathrm{M}=52.2 \%, \mathrm{SE}=2.4 \%$ ), abstract display ( $\mathrm{M}=54.5 \%$, $\mathrm{SE}=2.3 \%)$, or detailed display $(\mathrm{M}=53.1 \%, \mathrm{SE}=2.4 \%), \mathrm{F}[2,68.81]=.16, \mathrm{p}>.1$. The response 
target's role had a main effect on accuracy rate, $F[148.89]=62.77, \mathrm{p}<.001$. Post-hoc comparisons revealed significant differences between accuracy rates, such that responses about monks were less accurate $(\mathrm{M}=44.6 \%, \mathrm{SE}=1.6 \%)$ than responses about barbarians $(\mathrm{M}=57.3 \%, \mathrm{SE}=1.6 \%)$, $\mathrm{t}(148.64)=-.13, \mathrm{p}<.001$, and about clerics $(\mathrm{M}=57.9 \%, \mathrm{SE}=1.6 \%), \mathrm{t}(148.81)=-.13, \mathrm{p}<.1$. The difference in the accuracy of responses about barbarians and those about clerics was not significant, $\mathrm{t}(149.21)=-.01, \mathrm{p}>.1$. The model indicated a significant interaction between awareness display type and response target, $\mathrm{F}[4,148.68]=3.65, \mathrm{p}<.01$, but post-hoc comparisons revealed no significant differences. And again, there was a significant difference in the percentage of correct responses based on whether a participant was answering questions about oneself $(\mathrm{M}=59.1 \%, \mathrm{SE}=1.6 \%)$ than when answering questions about others $(\mathrm{M}=47.4 \%$, $\mathrm{SE}=1.3 \%), \mathrm{F}[1,145.84]=93.21, \mathrm{p}<.001$.

Generally, this pattern holds true when examining each time period individually. There were no significant differences in the percentage of correct responses based on awareness display type after time period $1(\mathrm{~F}[2,77.00]=.05, \mathrm{p}>.1)$, time period $2(\mathrm{~F}[2,75.45]=.50, \mathrm{p}>.1)$, or time period $3(\mathrm{~F}[2,72.21]=.57, \mathrm{p}>.1)$. Descriptive values for these three time periods are displayed in the table below.

\begin{tabular}{|l|l|l|l|}
\hline & Tailored Display & Abstract Display & Detailed Display \\
\hline Time Period 1 & $\mathrm{M}=46.4 \% \mathrm{SE}=3.0 \%$ & $\mathrm{M}=46.3 \% \mathrm{SE}=3.0 \%$ & $\mathrm{M}=43.6 \% \mathrm{SE}=3.1 \%$ \\
\hline Time Period 2 & $\mathrm{M}=53.5 \% \mathrm{SE}=2.6 \%$ & $\mathrm{M}=57.5 \% \mathrm{SE}=2.6 \%$ & $\mathrm{M}=53.3 \% \mathrm{SE}=2.7 \%$ \\
\hline Time Period 3 & $\mathrm{M}=56.8 \% \mathrm{SE}=2.8 \%$ & $\mathrm{M}=60.2 \% \mathrm{SE}=2.7 \%$ & $\mathrm{M}=61.0 \% \mathrm{SE}=2.8 \%$ \\
\hline
\end{tabular}

Table 5: Descriptives for the Percentage of Correct Responses on "During Task Survey" Time

Periods 1-3

Response target role also had a main effect the accuracy rate of responses after time period $1, F[2,356.50]=20.19, \mathrm{p}<.001$, and with post-hoc comparisons highlighting that accuracy 
was lower for responses about monks $(\mathrm{M}=37.9 \%, \mathrm{SE}=2.1 \%)$ than responses about barbarians $(\mathrm{M}=47.5 \%, \mathrm{SE}=2.1 \%), \mathrm{t}(356.27)=-9.6 \%$ or responses about clerics $(\mathrm{M}=50.8 \%, \mathrm{SE}=2.1 \%)$, $\mathrm{t}(357.06)=-12.9 \%, \mathrm{p}<.001$, but that the difference between the accuracy rates for responses about barbarians and clerics was not significant, $\mathrm{t}(356.17)=-3.3 \%, \mathrm{p}>.1$. After time period 2 , the main effect held, $\mathrm{F}[2,364.18]=26.72, \mathrm{P}<.001$, with post-hoc comparisons indicating that participants were less correct when responding about monks $(\mathrm{M}=45.7 \%, \mathrm{SE}=2.0 \%)$ than when responding about barbarians $(\mathrm{M}=59.4 \%, \mathrm{SE}=2.0 \%), \mathrm{t}(363.38)=-13.7 \%, \mathrm{p}<.001$, or about clerics $(\mathrm{M}=59.3 \%$, $\mathrm{SE}=2.0 \%), \mathrm{t}(364.30)=-13.6 \%, \mathrm{p}<.001$, but that there was no significant difference between the percentage of correct responses provided about barbarians and clerics, $\mathrm{t}(364.86)=.01 \%, \mathrm{p}>.1$. After time period 3, the main effect was also present, $F[2,360.65]=27.22, \mathrm{p}>.001$, and the same pattern emerged in the post-hoc comparisons; accuracy rates were worse for responses about monks $(\mathrm{M}=50.0, \mathrm{SE}=2.0 \%)$ than responses about barbarians $(\mathrm{M}=64.9 \%, \mathrm{SE}=2.1 \%), \mathrm{t}(361.19)=-$ $14.8 \%, \mathrm{p}<.001$, or clerics $(\mathrm{M}=63.4 \%, \mathrm{SE}=2.0 \%), \mathrm{t}(359.78)=-13.4 \%, \mathrm{p}<.001$. but there was no significant difference between the accuracy of responses about barbarians and clerics, $\mathrm{t}(360.97)=1.5 \%, \mathrm{p}>.1$.

And as before, there were significant differences in the percentage of correct responses based on self vs. other assessment, such that participants that were responding about oneself responded more correctly than when participants were responding about other group members. Descriptive values and F-tests for all three of the time periods are detailed in the table below.

\begin{tabular}{|c|c|c|c|c|}
\hline & Self Assessment & $\begin{array}{l}\text { Other } \\
\text { Assessment }\end{array}$ & F-test & P-value \\
\hline Time Period 1 & $\begin{array}{l}\mathrm{M}=52.6 \% \\
\mathrm{SE}=2.2 \%\end{array}$ & $\begin{array}{l}\mathrm{M}=38.2 \% \\
\mathrm{SE}=1.9 \%\end{array}$ & $\mathrm{~F}[1,362.81]=56.58$ & $\mathrm{p}<.001$ \\
\hline Time Period 2 & $\begin{array}{l}\mathrm{M}=60.3 \% \\
\mathrm{SE}=2.0 \%\end{array}$ & $\begin{array}{l}M=49.3 \% \\
S E=1.6 \%\end{array}$ & $F[1,359.32]=33.13$ & $\mathrm{p}<.001$ \\
\hline
\end{tabular}




\begin{tabular}{|l|l|l|l|l|}
\hline Time Period 3 & $\begin{array}{l}\mathrm{M}=64.1 \% \\
\mathrm{SE}=2.1 \%\end{array}$ & $\begin{array}{l}\mathrm{M}=54.6 \% \\
\mathrm{SE}=1.7 \%\end{array}$ & $\mathrm{~F}[1,362.14]=24.99$ & $\mathrm{p}<.001$ \\
\hline
\end{tabular}

Table 6: Percentage of Correct Responses to "During Task Survey" Times 1-3

Additionally, the model for time period 1 revealed that participant role had a main effect on the percentage of correct responses, $F[2,118.32]=3.7, \mathrm{p}<.05$. Post-hoc comparisons revealed the difference in the percentage of correct responses between participants playing clerics and those playing barbarians were statistically significant, with participants playing clerics answering a higher percentage of questions correctly $(\mathrm{M}=50.7 \%, \mathrm{SE}=2.8 \%)$ than those playing barbarians did $(\mathrm{M}=41.0 \%, \mathrm{SE}=2.7 \%), \mathrm{t}(118.75)=9.8 \%, \mathrm{p}<.05$. The differences in the responses by participants playing clerics and those playing monks $(\mathrm{M}=44.5 \%, \mathrm{SE}=2.7 \%)$ were not significantly different, $\mathrm{t}(118.31)=6.2 \%, \mathrm{p}>.1$, nor were the differences in the responses by participants playing barbarians and those playing monks, $\mathrm{t}(117.70)=-3.6 \%, \mathrm{p}>.1$. After time period 2, there was also a main effect for participant role, $F[2,116.10]=6.09, p<.005$. Post-hoc comparisons indicated that the differences in the responses by participants playing clerics and those playing monks were statistically significant such that those playing clerics $(M=60.6 \%$, $\mathrm{SE}=2.3 \%$ ) had a higher percentage of correct responses than those playing monks did $(\mathrm{M}=49.9 \%, \mathrm{SE}=2.4 \%), \mathrm{t}(115.94)=10.7 \%, \mathrm{p}<.005$. Also, the difference in the percentage of correct responses between participants playing clerics and those playing barbarians were marginally significant with participants playing clerics answering a higher percentage of questions correctly than those playing barbarians did $(\mathrm{M}=53.7 \%, \mathrm{SE}=23 \%), \mathrm{t}(115.79)=6.9 \%$, $\mathrm{p}<.1$. There were no significant differences in the responses by those playing barbarians and those playing monks, $\mathrm{t}(116.58)=3.8 \%, \mathrm{p}>.1$. This main effect was not present following time period 3, however, $\mathrm{F}[2,127.36]=.57, \mathrm{p}>.1$. 
Next, the average magnitude of responses provided by participants to questions asked in the "during task survey" aggregated across time periods 1, 2, and 3 were examined. There were no significant differences in terms of the average magnitude of responses based on whether participants had access to the tailored display $(\mathrm{M}=1.38, \mathrm{SE}=.08)$, abstract display $(\mathrm{M}=1.39$, $\mathrm{SE}=.08)$, or detailed display $(\mathrm{M}=1.43, \mathrm{SE}=.08), \mathrm{F}[2,65.14]=.27, \mathrm{p}>.1$. There was a main effect for response target role, $F[2,146.38]=43.349, \mathrm{p}<.001$. Post-hoc comparisons revealed that there were significant differences in each of the comparisons, such that participants had stronger opinions in their responses about barbarians $(\mathrm{M}=1.55, \mathrm{SE}=.05)$ than in their responses about clerics $(\mathrm{M}=1.40, \mathrm{SE}=.05), \mathrm{t}(146.50)=.15, \mathrm{p}<.001$, or than in their responses about monks $(\mathrm{M}=1.29, \mathrm{SE}=.05), \mathrm{t}(146.27)=.30, \mathrm{p}<.001$. Participants also had stronger opinions in their responses about clerics than they did in their responses about monks, $t(146.36)=.15, \mathrm{p}<.001$. There was no interaction between response target role and awareness display type, however, F[4, $146.22]=.32, \mathrm{p}>.1$. The model also indicated that self vs. other assessment had a significant impact such that participants had more extreme responses about themselves $(\mathrm{M}=1.36, \mathrm{SE}=.05)$ than about others $(\mathrm{M}=1.26, \mathrm{SE}=.05), \mathrm{F}[1,143.81]=91.72, \mathrm{p}<.001$, but that there was no interaction between self vs. other assessment and awareness display condition, $\mathrm{F}[2,147.70]=.83$, $\mathrm{p}<.1$.

This pattern of responses in terms of condition, response target role, and self vs. other assessment effects held for each time period individually. There were no significant differences in the average magnitude of responses based on awareness display type after time period 1 $(\mathrm{F}[2,73.89]=.13, \mathrm{p}>.1)$, time period $2(\mathrm{~F}[2,73.15]=.02, \mathrm{p}>.1)$, or time period $3(\mathrm{~F}[2,66.60]=1.10$, $p>$.1.) Descriptive values for these three time periods are presented in Table 7 below. 


\begin{tabular}{|l|l|l|l|}
\hline & Tailored Display & Abstract Display & Detailed Display \\
\hline Time Period 1 & $\mathrm{M}=1.12 \mathrm{SE}=.08$ & $\mathrm{M}=1.14 \mathrm{SE}=.08$ & $\mathrm{M}=1.07 \mathrm{SE}=.08$ \\
\hline Time Period 2 & $\mathrm{M}=1.41 \mathrm{SE}=.08$ & $\mathrm{M}=1.41 \mathrm{SE}=.08$ & $\mathrm{M}=1.42 \mathrm{SE}=.08$ \\
\hline Time Period 3 & $\mathrm{M}=1.61 \mathrm{SE}=.09$ & $\mathrm{M}=1.63 \mathrm{SE}=.09$ & $\mathrm{M}=1.76 \mathrm{SE}=.09$ \\
\hline
\end{tabular}

Table 7: Magnitude of Responses to the "During Task Survey" Times 1-3

Response target role had a main effect through the individual time periods as well. After time period 1 this main effect was present, $F[2,356.11]=18.39, \mathrm{p}<.001$, with post-hoc comparisons revealing that participants had stronger opinions about barbarians $(\mathrm{M}=1.22$, $\mathrm{SE}=.05)$ than they did about monks $(\mathrm{M}=.96, \mathrm{SE}=.05), \mathrm{t}(355.94)=-.27, \mathrm{p}<.001$, and that participants had stronger opinions about clerics $(\mathrm{M}=1.14, \mathrm{SE}=.05)$ than they did about monks, $\mathrm{t}(356.48)=-.19, \mathrm{p}<.001$, but the difference in the magnitude of responses about barbarians and clerics was not significant, $\mathrm{t}(355.91)=.08, \mathrm{p}>$.1. This main effect was present after time period 2 as well, $\mathrm{F}[2,362.05]=23.06, \mathrm{p}<.001$, although post-hoc comparisons revealed a slightly different pattern, in that there were significant differences in all three comparisons such that participants had stronger opinions when responding about barbarians $(\mathrm{M}=1.57, \mathrm{SE}=.05)$ than when responding about clerics $(\mathrm{M}=1.39, \mathrm{SE}=.05), \mathrm{t}(362.54)=.17, \mathrm{p}<.001$, or monks $(\mathrm{M}=1.27, \mathrm{SE}=.05)$, $\mathrm{t}(361.55)=.30, \mathrm{p}<.001$. Participants also had stronger opinions when responding about clerics than when responding about monks, $\mathrm{t}(362.06)=.13, \mathrm{p}<.05$. After time period 3 , the pattern was similar to that observed after time period 2 in that there was a main effect for response target role, $\mathrm{F}[2,358.16]=24.88, \mathrm{p}<.001$, and with post-hoc comparisons revealing that there were significant differences in all three comparisons. Participants had stronger opinions when responding about barbarians $(\mathrm{M}=1.85, \mathrm{SE}=.06)$ than when responding about clerics $(\mathrm{M}=1.64$, $\mathrm{SE}=.06), \quad \mathrm{t}(358.27)=.21, \quad \mathrm{p}<.001, \quad$ or monks $\quad(\mathrm{M}=1.51, \quad \mathrm{SE}=.06), \quad \mathrm{t}(358.49)=.34, \quad \mathrm{p}<.001$. 
Participants also had stronger opinions when responding about clerics than when responding about monks, $\mathrm{t}(357.70)=.13, \mathrm{p}<.05$.

Again, there were significant differences in the average magnitude of responses based on self vs. other assessment, such that participants that were responding about oneself responded more extremely than when participants were responding about other group members. Descriptive values and F-tests for all three of the time periods are detailed in Table 8, shown below.

\begin{tabular}{|l|l|l|l|l|}
\hline & Self & Other & F-test & P-value \\
\hline Time 1 & $\mathrm{M}=1.26 \mathrm{SE}=.05$ & $\mathrm{M}=.95 \mathrm{SE}=.05$ & $\mathrm{~F}[1,356.28]=62.91$ & $\mathrm{p}<.001$ \\
\hline Time 2 & $\mathrm{M}=1.56 \mathrm{SE}=.05$ & $\mathrm{M}=1.27 \mathrm{SE}=.05$ & $\mathrm{~F}[1,367.48]=51.60$ & $\mathrm{p}<.001$ \\
\hline Time 3 & $\mathrm{M}=1.77 \mathrm{SE}=.06$ & $\mathrm{M}=1.56 \mathrm{SE}=.06$ & $\mathrm{~F}[1,358.28]=26.79$ & $\mathrm{p}<.001$ \\
\hline
\end{tabular}

Table 8: Self vs. Other Assessment on “During Task Survey” after Time Periods 1-3

In addition, the model for time period 1 revealed a significant difference in response by gender, such that men provided more extreme responses $(\mathrm{M}=1.21, \mathrm{SE}=.06)$ than women did $(\mathrm{M}=1.00, \mathrm{SE}=.06), \mathrm{F}[1,178.30]=5.178, \mathrm{p}<.05$. However, this main effect was not present after either time period 2, $F[1,174.00]=2.51, \mathrm{p}>.1$, or time period $3, \mathrm{~F}[1,175.63]=.06, \mathrm{p}>.1$.

In summary, the results regarding role ambiguity during the task do not support $\mathrm{H} 2$, as awareness display type had no effect on either the percentage of correct responses or the magnitude of those responses during any time period during the task, nor did awareness display type interact with any other variable. These findings further suggest that the increased level of detail present in the tailored and detailed displays did not help participants reduce ambiguity with respect to their roles within the group. Response target role impacted both the percentage of correct responses and the magnitude of those responses, with responses about the barbarian often being the role about which participants most correctly and strongly answered. This may be because the goblin killing activities of the barbarian were more readily apparent to participants, 
leading them to develop stronger and clearer opinions about that role. Furthermore, the same self vs. other assessment differences were present during the task, indicating that players consistently understood their roles better than the roles of other group members. The impact of player role on the percentage of correct responses suggested that participants who played clerics were more accurate in their responses during the earlier time periods was unexpected and surprising.

\section{Performance}

$\mathrm{H} 3$ regarded the effect on awareness display type on performance on the task overall, and predicted that participants in groups with access to the tailored awareness display would perform better than participants in groups with access to either the abstract or the detailed awareness displays. Two measures of performance were used: the number of goblins a participant killed and the number of time a participant's avatar died.

To test H3, two linear mixed models were created, with the total number of goblin kills and player deaths each player had for the entire task as dependent variables. In each model awareness display type, player role, gender, total hours of video games played in the last week, the interaction between player role and awareness display type, and the interaction between total hours of video games played in the last week and awareness display type were set as fixed variables. H3 was not supported, as the results do not indicate that participants with access to the tailored display performed better than others overall, although there is support for the tailored display improving performance under specific circumstances.

In terms of overall goblin kills during the task, the model revealed a significant effect in the number of goblins that participants killed whether they were in groups had access to the tailored display $(\mathrm{M}=8.48, \mathrm{SE}=.48)$, abstract display $(\mathrm{M}=9.49, \mathrm{SE}=.47)$, or the detailed display 
$(\mathrm{M}=9.78, \mathrm{SE}=.47), \mathrm{F}[2,174.00]=3.64, \mathrm{p}<.05$. However, post-hoc comparisons revealed no significant differences between any of the display conditions.

However, the model did reveal a significant interaction between awareness display type and total hours of video games played in the week prior to the study, $F[2,174.00]=3.51, p<.05$. Fixed effects tests showed that, when compared to participants who used the detailed display condition, participants who used the tailored display killed an average of .17 more goblins per hour of video games they had played the week before, $\mathrm{t}(174.00)=.26, \mathrm{p}<.05$. There were no significant differences between the detailed display condition and the abstract condition in this regard, $\mathrm{t}(174.00)=.14, \mathrm{p}>.1$.

Additionally, the model revealed that there was a significant effect for player role, $\mathrm{F}[2$, $174.00]=82.72, \mathrm{p}<.002$. Not surprisingly, post-hoc comparisons revealed that participants playing barbarians killed more goblins $(\mathrm{M}=14.11, \mathrm{SE}=.47)$ than either participants playing clerics $(\mathrm{M}=5.92, \mathrm{SE}=.47), \mathrm{t}(147.00)=8.19, \mathrm{p}<.005$, or participants playing monks $(\mathrm{M}=7.72$, SE.47), $\mathrm{t}(147.00)=6.39, \mathrm{p}<.005$. Participants playing monks also killed more goblins than participants playing clerics, $\mathrm{t}(147.00)=1.80, \mathrm{p}<.05$. There was no significant interaction between awareness display type and player role, however, $\mathrm{F}[4,174.00]=.47, \mathrm{p}>.1$.

For the other component of performance, player deaths, the model indicated a marginally significant effect for awareness display type in the number of times that participants' avatars died, $F[2,66.24]=2.45, \mathrm{p}<.1$. Post-hoc comparisons revealed that there was a marginally significant difference between the abstract and tailored display, such that participants who had access to the abstract awareness display had fewer avatar deaths $(\mathrm{M}=4.42, \mathrm{SE}=.40)$ than participants who had access to the tailored awareness display $(\mathrm{M}=5.74, \mathrm{SE}=.42), \mathrm{t}(60.46)=-1.32$, $\mathrm{p}<.1$. There were no significant differences between participants with access to the abstract 
display and the detailed display $(\mathrm{M}=5.48, \mathrm{SE}=.41) \mathrm{t}(59.23)=-1.06, \mathrm{p}>.1$, nor between participants with access to the detailed display and the tailored display, $\mathrm{t}(59.23)=-.27, \mathrm{p}>.1$.

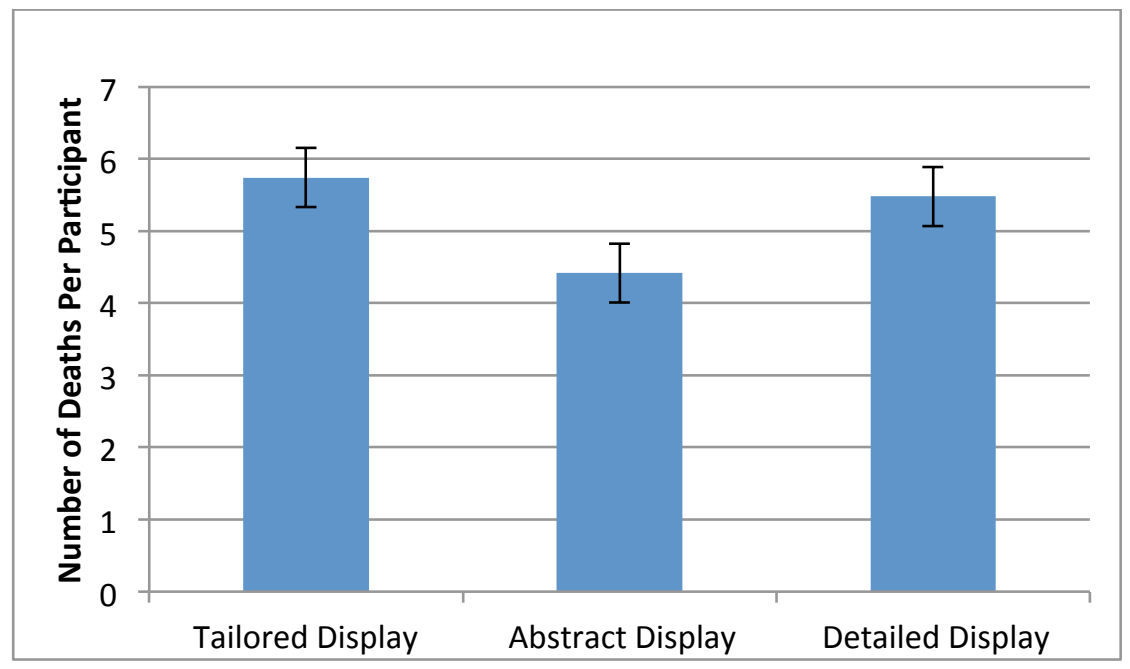

Figure 11: Number of Player Deaths by Display Condition

Again, the model revealed that there was a significant effect for player role, $\mathrm{F}[2$, 115.17] $=9.24, \mathrm{p}<.001$. Post-hoc comparisons illustrated that participants playing monks had fewer avatar deaths $(\mathrm{M}=4.41, \mathrm{SE}=.30)$ than participants playing barbarians $(\mathrm{M}=5.08, \mathrm{SE}=.30)$, $\mathrm{t}(115.11)=-1.07, \mathrm{p}<.01$. Participants playing monks also had fewer player deaths than participants playing clerics $(\mathrm{M}=5.75, \mathrm{SE}=.30), \mathrm{t}(115.02)=-1.35, \mathrm{p}<.001$. The differences in avatar deaths between participants playing barbarians and those playing clerics was not significant, however, $\mathrm{t}(115.39)=-.28, \mathrm{p}>.1$.

Summarizing these findings on overall performance on the task as measured by goblin kills and player deaths, H3 was not supported, as there were no significant differences between any of the display types of goblin kills, and the abstract display was more beneficial for performance than the tailored display was for player deaths. However, for more experienced players, the role tailored display was more beneficial for killing goblins, although not for 
preventing player deaths. This suggests that prior experience may be important when deciphering a familiar yet previously unseen awareness display, although this benefit may vary by activity type.

In addition to overall performance, awareness display type may impact performance over time, as group members may use tailored displays to learn about their role in the group, which they can then apply to future group tasks. As such, H4 predicted that participants in groups with access to the tailored display would show greater improvement over the course of the task than participants in groups with access to either the abstract or detailed displays.

The task was divided into four time periods, as the game was paused at two, five, and ten minutes during the task. To create three equal time periods, the goblin kills and player deaths for time periods one and two were summed, which yielded three five-minute time periods.

To test H4, two linear mixed models were created, with the sum of the goblin kills and player deaths broken up into the three time periods described above. In each model, awareness display type, player role, gender, time period total hours of video games played in the last week, the interaction between player role and awareness display type, the interaction between time period and awareness display condition, and the interaction between total hours of video games played in the last week and awareness display type were set as fixed variables. H4 was partially supported, as there were no significant differences in performance over time by display type for goblin kills, but participants in groups with the tailored display had greater improvement in their scores over time than participants in groups with access to either the abstract or detailed displays.

In this case, the variables of interest are the time period and the interaction between time period and awareness display type, as significant findings for non-time related variables are very similar to the overall performance findings. In terms of goblin kills, there was no effect for time 
period overall, as the differences in the number of goblins that participants killed were not significantly different depending on whether they were in the first five-minute time period $(\mathrm{M}=3.10, \mathrm{SE}=.14)$, the second $(\mathrm{M}=3.14, \mathrm{SE}=.14)$, or the third $(\mathrm{M}=3.01, \mathrm{SE}=.14), \mathrm{F}[2,368.00]=$ $.29, \mathrm{p}>$.1. Furthermore, there was no significant interaction between awareness display type and time period, $\mathrm{F}[4,368.00]=.42, \mathrm{p}>.1$.

Lastly, in terms of player deaths over time, there was a significant main effect for time period, $F[2,484.68]=20.00, \mathrm{p}<.001$. Post-hoc comparisons revealed that there was a significant difference between the first and second time periods such that participants' avatars died more frequently during the first time period $(\mathrm{M}=2.18, \mathrm{SE}=.10)$ than during the second time period $(\mathrm{M}=1.62, \mathrm{SE}=.10), \mathrm{t}(482.61)=.56, \mathrm{p}<.001$. The difference between the first and third time periods were also significant, with participants' avatars dying more frequently during the first time period than the third period $(\mathrm{M}=1.41, \mathrm{SE}=.10), \mathrm{t}(482.61)=.77, \mathrm{p}<.001$. The difference in avatar deaths between the second and third periods was not significant, however, $\mathrm{t}(482.61)=.27, \mathrm{p}>.1$.

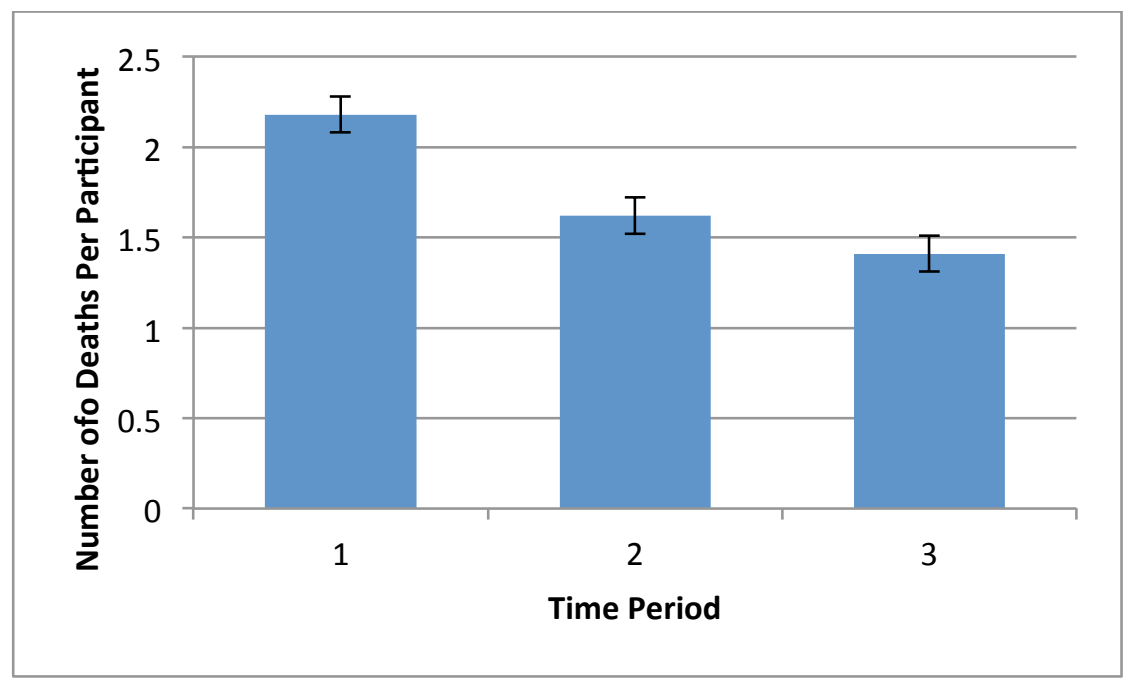

Figure 12: Overall Player Deaths by Time Period 
There was a significant interaction between awareness display type and time period, $\mathrm{F}[4,484.62]=8.7, \mathrm{p}<.001$. Post-hoc comparisons indicated that when participants were in groups that had access to the tailored display, they had more avatar deaths in time period $1(\mathrm{M}=2.89$, $\mathrm{SE}=.18)$ than in either time period $2(\mathrm{M}=1.45, \mathrm{SE}=.18)$ or time period $3(\mathrm{M}=1.40, \mathrm{SE}=.18)$, but that time periods 2 and 3 were not significantly different (see table below for all inferential statistics). When participants were in groups that had access to the detailed display, they had more avatar deaths in time period $1(\mathrm{M}=2.07, \mathrm{SE}=.18)$ than in time period $3(\mathrm{M}=1.57, \mathrm{SE}=.18)$, but there were no significant differences between time periods 1 and $2(\mathrm{M}=1.83, \mathrm{SE}=.18)$ or between time periods 2 and 3 . When participants had access to the abstract display, there was no difference in the number of player deaths between time periods $1(\mathrm{M}=1.57, \mathrm{SE}=.17), 2(\mathrm{M}=1.57$, $\mathrm{SE}=.17)$, or $3(\mathrm{M}=1.27, \mathrm{SE}=.17)$.

\begin{tabular}{|l|l|l|l|}
\hline Awareness Type & Time Periods & T-test & P-value \\
\hline Tailored Display & 1 vs. 2 & $\mathrm{t}(484.68)=1.45$ & $\mathrm{p}<.001^{* *}$ \\
\hline & 1 vs. 3 & $\mathrm{t}(484.68)=1.49$ & $\mathrm{p}<.001^{* *}$ \\
\hline & 2 vs. 3 & $\mathrm{t}(484.68)=.42$ & $\mathrm{p}>.1$ \\
\hline Abstract Display & 1 vs. 2 & $\mathrm{t}(484.68)=-.00$ & $\mathrm{p}>.1$ \\
\hline & 1 vs. 3 & $\mathrm{t}(484.68)=.31$ & $\mathrm{p}>.1$ \\
\hline Detailed Display & 2 vs. 3 & $\mathrm{t}(484.68)=.31$ & $\mathrm{p}>.1$ \\
\hline & 1 vs. 2 & $\mathrm{t}(484.68)=.24$ & $\mathrm{p}>.1$ \\
\hline & 1 vs. 3 & $\mathrm{t}(484.68)=.51$ & $\mathrm{p}<.05^{* *}$ \\
\hline & 2 vs. 3 & $\mathrm{t}(484.68)=.26$ & $\mathrm{p}>.1$ \\
\hline
\end{tabular}

Table 9: Player Deaths by Time Period and Awareness Display Condition 


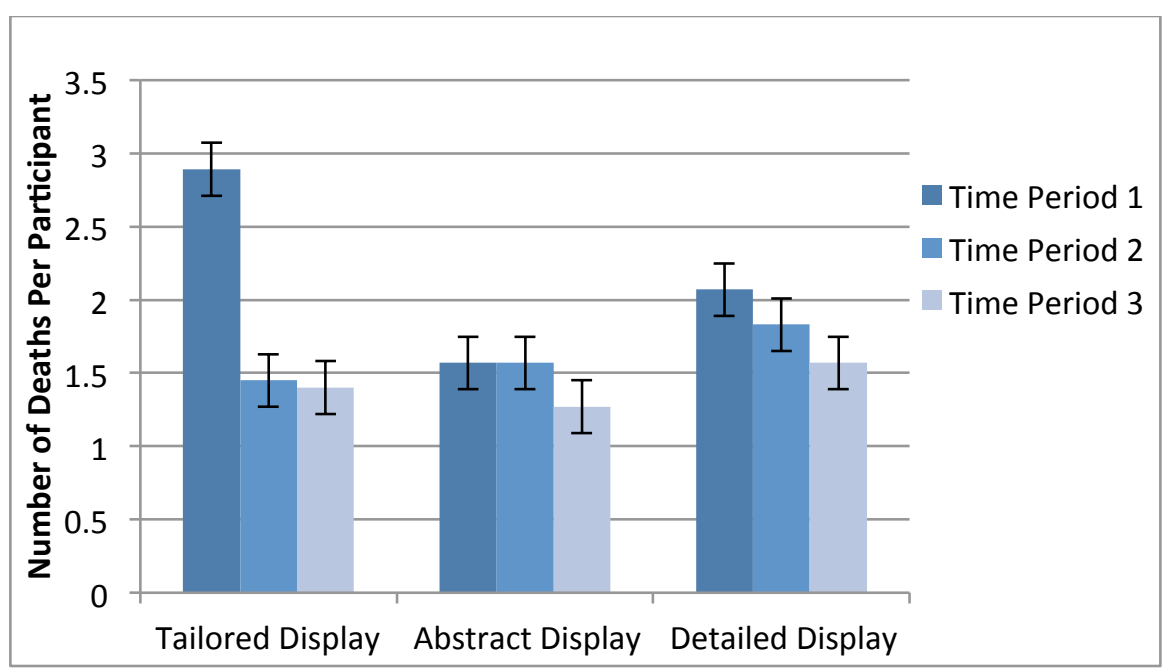

Figure 13: Player Deaths by Time Period and Awareness Display Condition

In terms of performance over time, there was no effect of awareness display type on performance improvement for killing goblins, suggesting that all displays were equally effective at facilitating performance in this respect. There was, however, a significant interaction between awareness display type and time period for player deaths. Participants in groups that used the tailored display performed significantly better during the second and third time periods as compared with the first periods, indicating a period of sharp improvement followed by steady performance. Participants in groups that used the detailed display also showed evidence of improvement in that their performances in the third time periods was significantly better than the first periods, but their improvement was more gradual as there were no significant differences in adjacent time periods. In contrast, there were no significant differences in performance by time period for participants in groups that used the abstract display, suggesting that those groups maintained a consistent level of performance over time. 


\section{Task and Social Satisfaction}

H5 posited that participants in groups that used the tailored awareness display would report higher levels of task satisfaction than participants in groups that used either the abstract or the detailed display, as the benefits of having a clear understanding of their role would lead to a better experience performing the task. To test H5, two linear mixed models were created with average scores on the NASA Task Load Index (Hart and Staveland, 1988) and average scores on the task attraction portion of the Interpersonal Attraction Scale (McCroskey et al., 1974) as the dependent variables. The models were constructed with awareness display type, player role, gender, total hours of video games played in the last week, the interaction between player role and awareness display type and the interaction between total hours of video games played in the last week and awareness display type set as fixed variables. Additionally, the model for the task attraction portion of the Interpersonal Attraction Scale also included which group member was the target of the response and the interaction between response target and awareness display condition as fixed variables. H5 was not supported, as there were no differences in the responses to either measure based on awareness display type.

In terms of task load, there was no main effect of awareness display type on the average response score to the NASA Task Index, as there were no significant differences in participant responses based on whether they were in groups that had access to the tailored display ( $M=8.70$, $\mathrm{SE}=.47)$, abstract display $(\mathrm{M}=8.30, \mathrm{SE}=.47)$, or detailed display $(\mathrm{M}=9.18, \mathrm{SE}=.46), \mathrm{F}[2$, 73.86] $=1.58, \mathrm{p}>.1$. There were no other main effects or interactions in the model.

In terms of task satisfaction with group members, there was also no main effect of awareness display type on the average response score to the task attraction portion of the Interpersonal Attraction Scale, as there were no significant differences in participant responses 
based on whether they were in groups that had access to the tailored display $(\mathrm{M}=4.81, \mathrm{SE}=.12)$, abstract display $(\mathrm{M}=4.94, \mathrm{SE}=.12)$, or detailed display $(\mathrm{M}=4.73$, $\mathrm{SE}=.11), \mathrm{F}[2,75.58]=1.79$, $p>.1$. The model did reveal a significant main effect for response target, $F[2,188.58]=1.27$, $\mathrm{p}<.05$. Post hoc comparisons revealed that there was a marginally significant difference in the average of responses about barbarians and the responses about clerics, such that responses about barbarians were more favorable $(\mathrm{M}=4.92, \mathrm{SE}=.09)$ than responses about clerics $(\mathrm{M}=4.67$, $\mathrm{SE}=.09), \mathrm{t}(182.55)=.25, \mathrm{p}<.1$. There was also a marginally significant difference in the average of responses about monks and the responses about clerics, such that responses about monks were more favorable $(\mathrm{M}=4.91, \mathrm{SE}=.09)$ than responses about clerics, $\mathrm{t}(184.69)=.24, \mathrm{p}<.1$. The difference between responses about barbarians and responses about monks were not significant, however, $\mathrm{t}(185.93)=.01, \mathrm{p}>.1$. The interaction between response target and awareness display type was also not significant, $F[4,184.34]=1.52, \mathrm{p}>.1$.

Overall, these findings on task satisfaction do not support H5, as awareness display type had no main effect on responses to either measure and there were no significant interactions with awareness display type to responses on either measure. In terms of task satisfaction, participants had a more positive opinion about the competency and capability of those playing barbarians and monks than they did about those playing clerics. One interpretation for this is that the cleric had abilities that could only be used once each before needing to refresh them using the "rest" function, whereas the monk and barbarian could use their abilities consistently throughout the task. As a result, the cleric would be the one most likely in the group to be unable to perform her duties, which may be reflected in this inter-personal assessment.

H6 predicted that participants in groups that used the tailored awareness display would report higher levels of social satisfaction with their fellow group members than participants in 
groups that used either the abstract or the detailed awareness displays. To test H6, a linear mixed model was constructed with average scores on the social attraction portion of the Interpersonal Attraction Scale as the dependent variable, and with awareness display type, player role, response target, gender, total hours of video games played in the last week, the interaction between player role and awareness display type, the interaction between response target and awareness display type, and the interaction between total hours of video games played in the last week and awareness display type set as fixed variables.

H6 was not supported, as there was no main effect for awareness display type; there were no significant differences in participants' responses about social satisfaction based on whether they used the tailored display $(\mathrm{M}=4.70, \mathrm{SE}=.11)$, the abstract display $(\mathrm{M}=4.88, \mathrm{SE}=.12)$ or the detailed display $(\mathrm{M}=4.72, \mathrm{SE}=.11), \mathrm{F}[2,76.30]=1.32, \mathrm{p}>.1$. There were no other main effects or interactions in the model. Therefore, it appears that participants held relatively high opinions of each other regardless of the conditions of the experiment.

\section{Communication}

In terms of communication during the task, $\mathrm{H} 7, \mathrm{H} 8$, and $\mathrm{H} 9$ were concerned with participants' discussions of roles, looking at all role communication, role ambiguity statements, and questions about roles respectively. All three of these hypotheses predicted that participants in groups using the tailored display would make fewer statements than participants in groups using the abstract or detailed displays, as the tailored display would better provide participants with information about their own and others' role, thus reducing the need to explicitly communicate this information during the task.

H7 regarded the role statements overall, which includes statements reflecting both a positive and negative understanding of one's and others' roles in the group. To test H7, a linear 
mixed model was created with the total of role-related statements as the dependent variable. This variable was created by summing all of the role categories from the coding scheme. Awareness display type, player role, gender, total hours of video games played in the last week, the interaction between player role and awareness display type, and the interaction between total hours of video games played in the last week and awareness display type were set as fixed variables.

H7 was not supported, as there were no significant differences in the total number of rolerelated statements by participants in groups using the tailored display $(\mathrm{M}=.19, \mathrm{SE}=.08)$, the abstract display $(\mathrm{M}=.28, \mathrm{SE}=.08)$, or the detailed display $(\mathrm{M}=.15, \mathrm{SE}=.08), \mathrm{F}[2,66.92]=.15$, $\mathrm{p}>$.1. The model did reveal a significant main effect for gender, $F[1,153.18]=6.011, \mathrm{p}<.05$. Posthoc comparisons revealed a significant difference such that males provided more role-related statements $(\mathrm{M}=.29, \mathrm{SE}=.06)$ than females $\operatorname{did}(\mathrm{M}=.129, \mathrm{SE}=.06), \mathrm{t}(153.18)=.16, \mathrm{p}<.05$. These findings suggest that not only did the type of awareness display not impact the amount that participants talked about roles, but that communication about roles was infrequent. One reason for this may be that given the relatively short duration of the task, participants were more focused on more urgent issues such as coordinating a strategy for attack and resting, and less focused on higher level group issues such as the ideal role for each person.

H8 involved the number of explicit statements regarding role ambiguity (i.e., the number of explicit incorrect statements about either one's or others' roles in the group). To test H8, a linear mixed model was created with the total of explicit role ambiguity statements as the dependent variable. This variable was created by summing statements from the "negative explicit reference about self role" and "negative explicit reference about another's role" categories from the coding scheme. Awareness display type, player role, gender, total hours of video games 
played in the last week, the interaction between player role and awareness display type, and the interaction between total hours of video games played in the last week and awareness display type were set as fixed variables.

H8 was not supported; there was no main effect for awareness display type, as there were no significant differences in the total number of role ambiguity statements by participants in groups using the tailored display $(\mathrm{M}=.05, \mathrm{SE}=.02)$, abstract display $(\mathrm{M}=.06, \mathrm{SE}=.02)$, or detailed display $(\mathrm{M}=.03, \mathrm{SE}=.03), \mathrm{F}[2,69.65]=.24, \mathrm{p}>.1$. There were no other main effects or interactions in the model. Again, this indicates that either role ambiguity was not a common topic of conversation among participants, or that all three displays did an equally good job of conveying role information to participants such that they did not often make incorrect statement about their or others' roles.

H9 centered on the number of questions about roles asked by participants during the study. To test H9, a linear mixed model was created with the total of explicit role ambiguity statements as the dependent variable. This variable was created by summing statements from the "negative explicit reference about self role" and "negative explicit reference about another's role" categories from the coding scheme. Awareness display type, player role, gender, total hours of video games played in the last week, the interaction between player role and awareness display type, and the interaction between total hours of video games played in the last week and awareness display type were set as fixed variables.

H9 was not supported, as there were no significant differences in the total number of role ambiguity statements by participants in groups using the tailored display $(\mathrm{M}=.04, \mathrm{SE}=.03)$, the abstract display $(\mathrm{M}=.08, \mathrm{SE}=.02)$, or the detailed display $(\mathrm{M}=.05, \mathrm{SE}=.03), \mathrm{F}[2,69.97]=.37$, $p>$.1. There were no other main effects or interactions in the model. These findings further 
highlight how infrequently either one's own or other group members' roles were a topic of discussion during the study. 


\section{CHAPTER 8}

\section{DISCUSSION}

This study explored the impact of visual awareness display type on role ambiguity during group work in an online video game environment. Participants completed a collaborative task in the game Neverwinter Nights, and were presented with one of three types of displays that provided information about themselves and other group members: a tailored display, which emphasized information about participants' own roles while abstracting information about others' roles, an abstract display that abstracted information about all three participants' roles, or a detailed display which emphasized information about all three participants' roles. The predicted effects of awareness display type were tested in an empirical study, with results suggesting that each display type had an advantage under specific circumstances.

\section{Role Ambiguity}

In terms of role ambiguity, the type of awareness display that participants used had no impact on their responses to the Role Ambiguity Scale or the strength of their opinions on the "during task survey." The type of display did affect how accurately participants could identify what each group member was able to do by the completion of the task, however, with a trend toward the detailed display being the best style for making these types of assessments. This overall trend was impacted by the role about which participants were answering, as the detailed display was particularly beneficial in terms of being able to accurately identify what the cleric role was able to do, and the tailored display was particularly unhelpful for accurately identifying what the barbarian and monk roles were able to do. 
Since there were no effects for display type on the experience of role ambiguity, which is different than being able to identify what different roles were responsible for or the strength of opinions about different roles, it is hard to situate this within the role episode model framework (Kahn et al., 1964). One explanation is that the amount of tailoring of information in the awareness displays has no impact on how much role ambiguity individuals experience when working in a distributed group, meaning that there are other factors which impact role ambiguity under these circumstances (e.g., task type, prior experience, etc.) However, there are several other possible reasons why the type of awareness display presented to participants did not impact feelings of role ambiguity. For example, the implementation of the design may not have worked as intended, such that there was a disconnect between the idea of tailoring information for individual roles and the execution of that idea. This would mean that information tailoring may still have value for understanding role ambiguity in distributed groups, just not in the way that it was conceived in this study.

A second possible alternate explanation is that tailoring of information is important for role ambiguity and the design was executed appropriately, but that participants did not understand the displays well enough to get use out of them during this experiment. There is some evidence of participants being confused by the detailed or abstracted elements of the display (except for the colorized ability icons, when present.) For example, the monk in group $1011 \mathrm{did}$ not understand what the obvious target effect represented, as he asked "what's [sic] the white circles?" Although he had the reference sheet which identified what the visual effects meant, there was no indication that he ever figured out what they meant. In another instance of confusion, the participant playing the cleric in group 1009 asked "what are those white circles that show up around our heads?," which indicated that she did not understand what the subtle 
target effect represented. In this instance, the participant playing the barbarian did understand, and responded, "the white circles mean you're the monster's target." The health bar also confused participants such as the one playing the monk in group 2011, who could not understand how to tell when he needed to rest or ask for a healing spell from the cleric. The participant playing the barbarian responded, "the health bar...when it turns red you need more health," to which the monk responded "oh oops." Participants also commented on being confused by the damage dealt visual effect. This confusion hints at a broader lack of understanding of the displays for many participants, which means that they might not have correctly understood what information the displays were conveying, which would undermine the experimental manipulation.

Although it was not associated with feelings of role ambiguity, participants' accuracy at identifying what each role was responsible for was somewhat impacted by the type of awareness display used, with a trend toward the detailed display being the best for this. This suggests that rather than tailoring information to individuals' roles, that it is best to provide them with rich, detailed information about the activities of others and allow them to filter this information to make assessments about roles and responsibilities. This finding appears to be the digital equivalent of how individuals in collocated settings accurately identify which group members are responsible for given tasks (Bechky, 2006), and that filtering or abstracting this information is not beneficial. Individuals were also not uniformly accurate at identifying the responsibilities of each role, which suggests that factors other than the awareness display are important when thinking about roles and role awareness in distributed groups. 


\section{Performance}

In terms of the goblin kills aspect of performance, there was a trend toward the detailed display being the best for improving participants' ability to kill goblins overall. In terms of the number of times that participants' avatars died during the task, the abstract display was the best for improving performance in this respect, and there was no interaction between frequency of video game play and awareness display type for this measure. This suggests that, contrary to Zhu's (2004) arguments about the advantages of WYSINIS style awareness displays, that more traditional WYSIWIS or relaxed WYSIWIS type displays are most beneficial for performance overall. However, there was an interesting interaction between awareness display type and how often participants played video games in terms of the number of goblins that participants killed during the task, such that more frequent video game players killed more goblins than less frequent players, but only when they used the tailored display. This interaction illustrates that although WYSIWIS type displays may be best for promoting performance overall, that Zhu's (2004) arguments about the usefulness of tailored WYSINWIS displays may be more appropriate for expert users than less experienced users, depending on the nature of the task being performed.

One explanation for these findings about performance involves the amount of collaboration involved for the two activities. The linear mixed models for the two activities indicated a difference in the amount of non-independence of responses; specifically, that the group that a given participant was in impacted how often their avatar died, but it did not impact how many goblins they killed. This indicates that although the respawn delay improved upon Reynolds et al. (2012) in terms of how participants strategized about the task, goblin killing was still a much less collaborative activity than avoiding avatar deaths. The difference in degree of 
collaboration between these two activities may help with the interpretation of these findings. For example, given that there were no differences in role ambiguity among the three groups, the abstract display being better for the avatar death prevention aspect of performance is expected based on past research regarding awareness displays and collaborative tasks (e.g., Dabbish and Kraut, 2004). However, for goblin killing, the less collaborative aspect of the task, there was not the same effect; this indicates that the advantages of the abstract display (e.g., reduced attentional costs and cognitive load) may be less beneficial to individuals engaged in less collaborative group tasks.

This difference may also help with understanding the effect of prior video game experience on killing goblins, in which more experienced players who used the tailored display performed better than less experienced players, but that the same pattern did not hold for participants using the detailed or abstract displays. While the detailed display, with its abundance of information, was the best overall, experienced players performed better when provided with detailed information about their role and abstracted information about the others. This finding, which was intriguing given the lack of support for the tailored display in every other regard, suggests that a tailored display may have advantages over either type of WYSIWIS-style display for those who presumably have more experience interpreting these types of displays. The difference in the amount of collaboration required for the two tasks may explain why this effect was not observed for preventing player deaths; an experienced video game player may have been able to take advantage of the benefits of the tailored display to kill more goblins without help, but would not have been able to do so to prevent avatar deaths. This presents opportunities for further research exploring the effects of tailored displays on performance during collaborative work, using groups where all participants are experienced in performing the experimental tasks. 
Another finding regarding performance was that, in terms of avoiding player deaths, there was evidence of improvement over time for groups using the tailored and detailed displays, but not for groups using the abstract display (despite the abstract display being best for avoiding player deaths overall.) The pattern of improvement between the two types of displays was different, however, with participants using the tailored display showing a sharp increase in performance followed by a plateau, whereas participants using the detailed display showed a more gradual but more consistent improvement over time. This finding may also stem from the varying attentional costs needed to interpret the displays, and the negative impact that may have on performance. The three displays varied in how detailed information was presented, with the abstract display having the fewest detailed elements (i.e., only elements of the display that were not modified for the study, such as player location), the tailored display having additional detailed elements for information about the user's role, and the detailed display having even more detailed elements for information about others' roles. If interpreting the detailed elements required more attention (e.g., Dabbish and Kraut, 2004), then that may have come at a cost to performance on the collaborative aspect of the task. The improvement over time suggests that as participants became more familiar with the detailed elements of the display, the attentional costs of using these displays decreases and approaches that of the abstract display.

\section{Communication}

Unfortunately, the type of awareness display that participants used did not have any effect on the number of overall role statements, statements about role ambiguity, or questions about roles uttered during the task. This suggests that none of the displays was particularly good at providing the types of information that reduced conversation, as observed in Gutwin and Greenberg (2002). Overall, unlike those observed in ad-hoc collocated group work (Beckhy, 
2006), participants did not talk much about roles during the task, indicating that it was not a key area of focus for these individuals. Instead, conversations were focused around discussing strategy, coordinating actions (e.g., "go now"), and coordinating rest periods between battles. One reason for this may be that in this very short-term, zero-history, one-off, non-professional group task, individuals were likely more concerned with more immediately pressing matters (such as coordinating for the task at hand) than about figuring out which group members could perform which actions.

Additionally, the experimental setup went to great lengths to not prime participants to think about roles (e.g., not mentioning roles in introductory materials, etc.), but this may have had the inadvertent effect of leading participants to assume that all group members had the same role. While it is impossible to speculate about the thoughts of participants who didn't talk about roles (or who didn't talk at all), there were numerous statements made by participants that suggested that they assumed the other group members had the exact same abilities as they did. For example, the monk in group 2005 wrote during the first time period "check out your perry [sic] move...F3," referencing the defensive ability that only the monk possessed, signaling that he believed the other two players had the same ability. This assumption continued, as he encouraged the barbarian to "try ur F3, should be pretty good" after the barbarian complained of dying too easily later in the task. Neither the barbarian nor the cleric corrected the monk's assumptions about their abilities, so he likely continued to believe they all had the same abilities for the duration of the task. In another example, the cleric in group 1004 suggested that everybody should heal each other during the battles, implying that she believed the other two players also possessed the two healing abilities. When the monk responded with confusion, the cleric continued explaining that there are two healing spells and told him where to find them. In 
this instance, however, the monk responded that he had different abilities in those spots and that he thought that only the cleric had the healing abilities, so the cleric's assumption was corrected. If other participants shared this same belief about all group members having the same abilities, it may have put a damper on role communication during the task.

\section{Implications for Design}

Unfortunately, there are few implications for the design of visual awareness displays to improve role clarity in distributed groups based on the findings of this study. Future work in this area could explore whether alternate ways of configuring displays under these conditions, or whether drawing from a participant pool more familiar with interpreting these types of displays impact role ambiguity in distributed groups.

It also appears that the design implications for the configuration of these types of displays also depends greatly on what one intends to promote, as each of the display types were the strongest under specific conditions. For example, if the primary goal is to promote the accurate identification of responsibilities within a group, the detailed display would be the best display type. However, if one wants to instead promote performance on a collaborative task, they should instead design an abstract display to provide information to group members. And if the goal is to promote performance on an individual task among participants with high experience, then the tailored display would be the best choice. This indicates a complicated relationship between awareness display types and outcomes that does not lend itself well to sweeping generalizations in terms of design recommendations. 


\section{Research Limitations}

There are several limitations to this study that may impact the interpretation of these findings. First, like many studies of this nature, this study draws on a student sample; this is a threat to the external validity of these findings, as the use of a student population could affect the generalizability of these findings to other populations. A second limitation of this study was that participant groups were formed on an ad-hoc basis, with individuals that had no prior history working together, and had no expectations to work together again in the future. While these type of virtual ad-hoc workgroups do occur in natural settings (Hinds and Kiesler, 2002), forming the participant groups in this way may also be a threat to the external validity of these findings, as this may limit the generalizability of these findings to other types of workgroups. For instance, this may have resulted in participants having much less motivation to care about their own or others' roles than individuals in groups that expected to work together again may have been. Future research in this area should explore how long-term distributed groups experience role ambiguity under these circumstances.

\section{Future Work}

The outcomes of this study highlight several avenues for further research regarding role ambiguity in distributed groups. As mentioned in the previous section, one approach is to expand to both broader populations and groups of individuals engaged in longer-term work, to improve the generalizability of these findings. The findings regarding player performance suggest that another avenue for further research is expanding this study to a population of individuals more experienced with viewing displays similar to the ones they would be using during the task (whether this is within a video game environment or a different type of environment), as the 
findings suggest that more experienced users got more benefit out of the tailored display than inexperienced users.

In addition to the research avenues proposed in earlier sections of the paper intended to refine or expand the current findings, the challenges to studying role ambiguity in distributed groups identified in this paper suggest that future work in this domain may need to take a more exploratory approach. For instance, this study did not provide any conclusive evidence that awareness display type impacted how the members of distributed groups experienced role ambiguity, which leaves open questions about which factors do impact role ambiguity in distributed groups, and whether these factors are different than those which impact role ambiguity in collocated groups as identified by Kahn et al. (1964). Therefore, future work in this area should identify other possible areas for exploration, such as communication channel type, availability and use of collaborative tools, or frequency and type of contact among group members. This could be done through interviews and observations of individuals working in distributed groups, with particular emphasis on situations where role ambiguity has been shown to be more likely to occur, such as when there is a change in the members of the group or when the group begins a novel task (e.g., Kahn et al., 1964, Van Sell et al., 1981).

\section{Conclusion}

This study explored the effects of different visual awareness display configurations on role ambiguity, performance, and communication about roles in distributed groups collaborating on a task within an online video game environment. The results of this study are not conclusive, as there were no effects of awareness display type on role communication during the task, the findings for role ambiguity were weak, and the performance findings did not paint a clear picture of which display was best overall. There are a number of reasons why this may have been the 
case, such as participants not understanding the display elements or assuming that all group members had the same role. Unfortunately, as a result, this study does little to advance our understanding of how role ambiguity functions in distributed groups. However, this study does identify several ways in which future research on role ambiguity in distributed groups can improve, such as ensuring that participants understand all elements of the awareness displays and constructing groups that are completing collaborative tasks over multiple sessions. 


\section{APPENDIX 1}

\section{TASK INTRODUCTION}

Today you will be completing a group task in an online video game. During this task, you will:

- Follow a path which contains enemy goblins

- Have $\mathbf{1 5}$ minutes to kill as many goblins as you can

- Be paused periodically to answer surveys

- Communicate with your group members using in-game text chat

- To type in the text box:

1. Press the enter key

2. Type your message

3. Press the enter key again

Each time your group defeats a goblin, your group earns 10 points. However, each time a member of your group dies, your team loses 3 points. Groups that participate in this task earn 164 points on average. To maximize your score, your group should defeat as many goblins as possible and minimize the number of times that your group members die.

Each time a player in your group dies, there will be a 15 second delay before that player can rejoin the battle. 


\section{APPENDIX 2}

\section{PLAYER REFERENCE SHEETS}

\section{Tailored Display Information - Barbarian}

\section{Health Meter}

The background of yours and group members' health meters will change depending on the given players' current health level. For example, when you are at full health, your health meter will look like this:

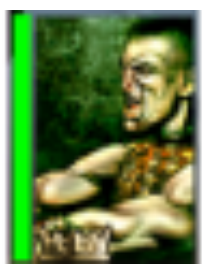

However, the color of the background will change such that at low health your health meter will look like this:

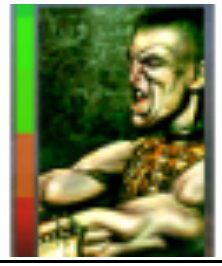

\section{Goblin LifeBar}

Each enemy goblin's current health will be represented with a lifebar that appears over its head like this:

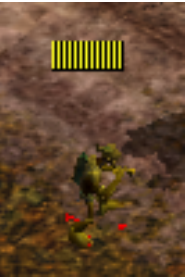

\section{Target Halo}

The player that is the current target of an enemy goblin will be designated with a "halo" as shown:

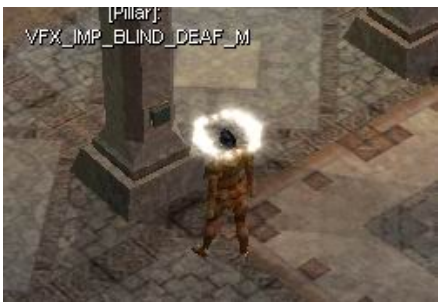




\section{Health Meter}

The background of your health meter will change depending on your current health level. When you are at full health, your health meter will look like this:

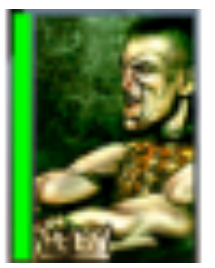

However, the color of the background will change such that at low health your health meter will look like this:

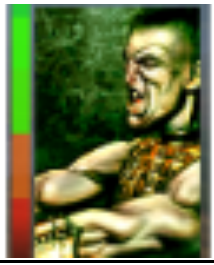

\section{Damage Flashes}

Each time a player deals damage to an enemy goblin, you will see the following animation around your character:

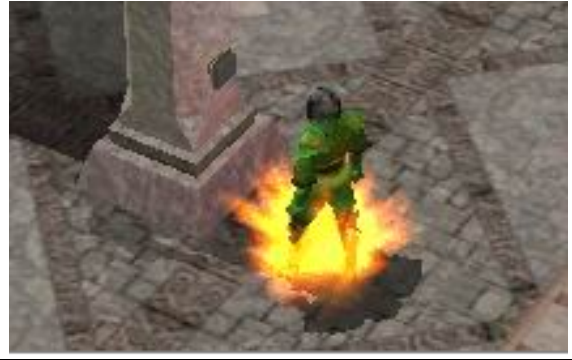

\section{Target Halo}

The player that is the current target of an enemy goblin will be designated with a "halo" as shown:

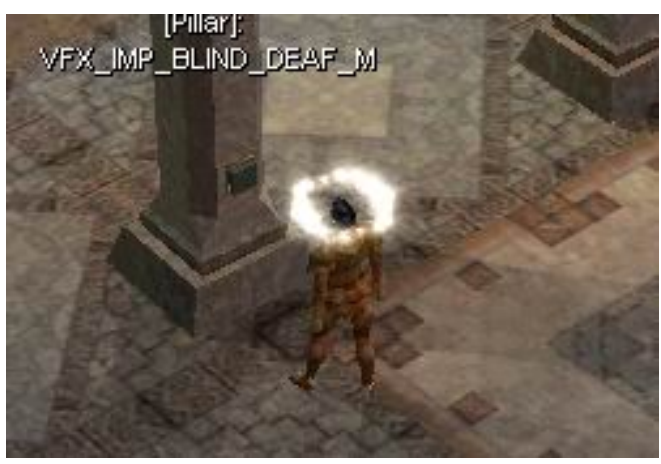




\section{Health Meter}

The background of yours and group members' health meters will change depending on the given players' current health level. For example, when you are at full health, your health meter will look like this:

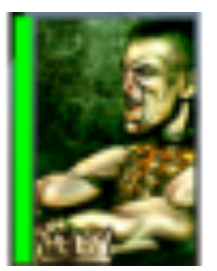

However, the color of the background will change such that at low health your health meter will look like this:

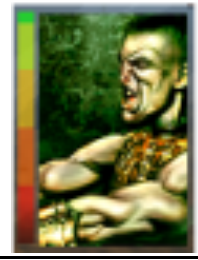

\section{Goblin LifeBar}

Each enemy goblin's current health will be represented with a lifebar that appears over its head like this:

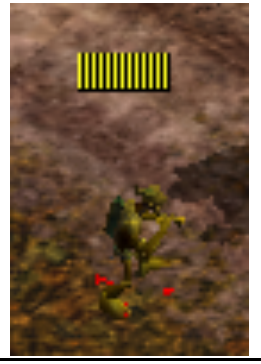

\section{Target Halo}

The player that is the current target of an enemy goblin will be designated with a "halo" as shown:

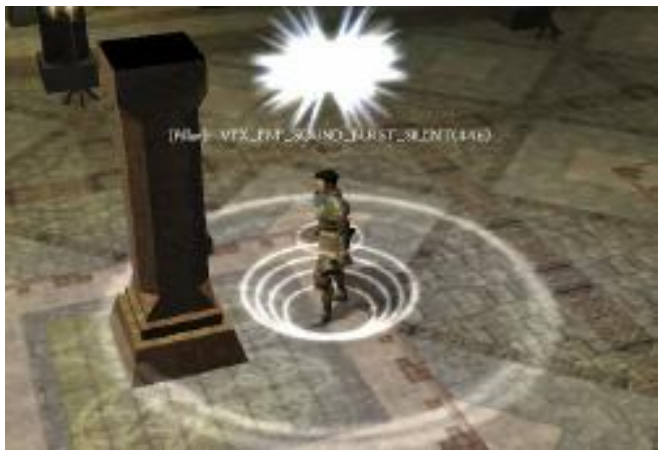




\section{Health Meter}

The background of yours and group members' health meters will change depending on the given players' current health level. For example, when you are at full health, your health meter will look like this:

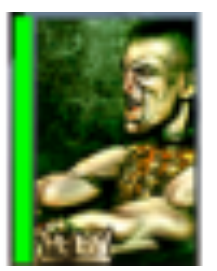

However, the color of the background will change such that at low health your health meter will look like this:

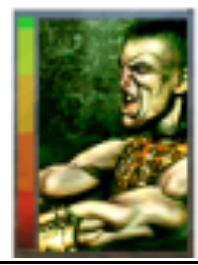

\section{Damage Flashes}

Each time a player deals damage to an enemy goblin, you will see the following animation around your character:

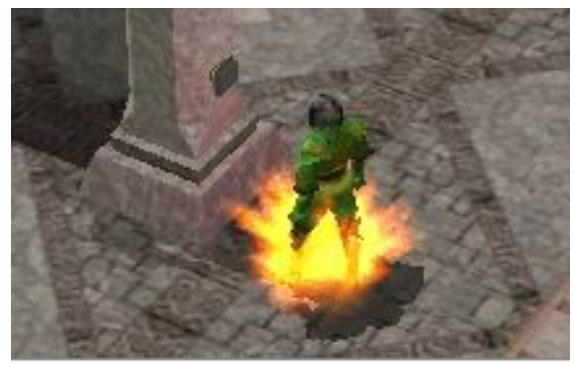

\section{Target Halo}

The player that is the current target of an enemy goblin will be designated with a "halo" as shown:

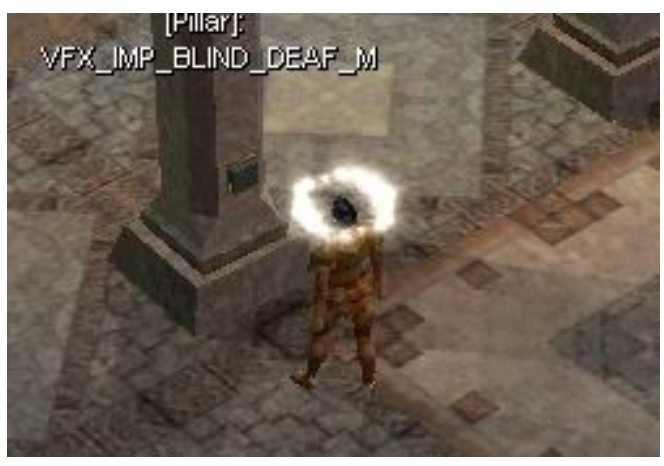




\section{Health Meter}

The background of your health meter will change depending on your current health level. When you are at full health, your health meter will look like this:

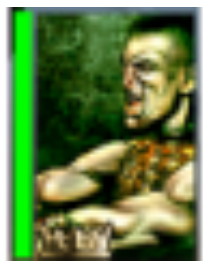

However, the color of the background will change such that at low health your health meter will look like this:

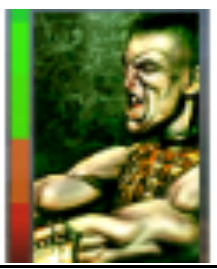

\section{Damage Flashes}

Each time a player deals damage to an enemy goblin, you will see the following animation around your character:

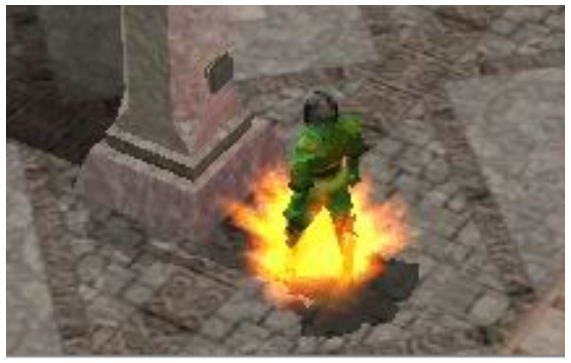

\section{Target Halo}

The player that is the current target of an enemy goblin will be designated with a "halo" as shown:

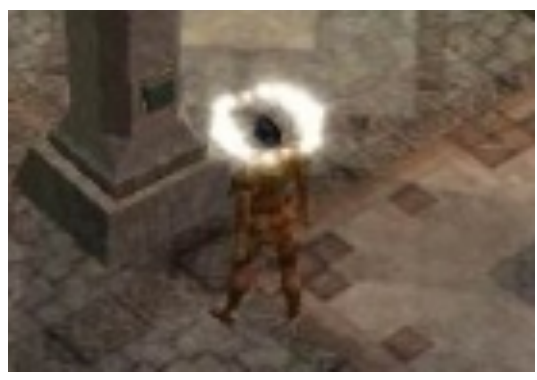




\section{Health Meter}

The background of yours and group members' health meters will change depending on the given players' current health level. For example, when you are at full health, your health meter will look like this:

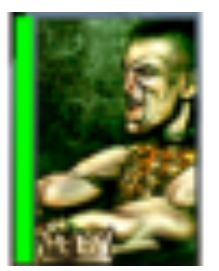

However, the color of the background will change such that at low health your health meter will look like this:

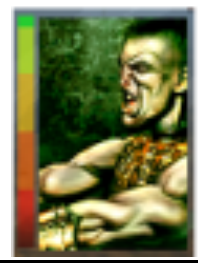

\section{Goblin LifeBar}

Each enemy goblin's current health will be represented with a lifebar that appears over its head like this:

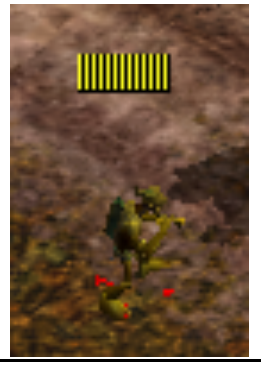

\section{Target Halo}

The player that is the current target of an enemy goblin will be designated with a "halo" as shown:

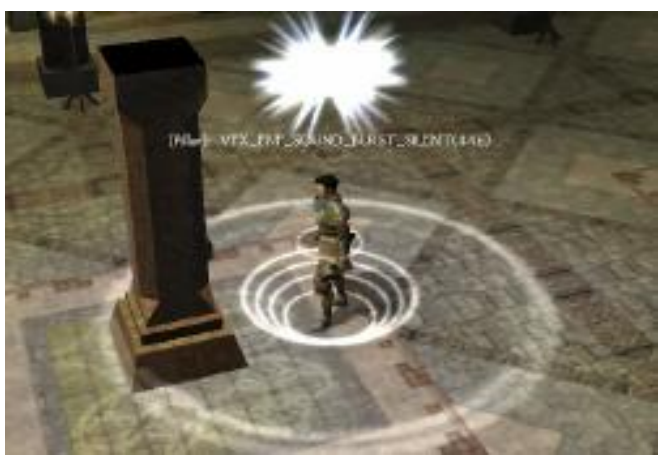




\section{Health Meter}

The background of your health meter will change depending on your current health level. When you are at full health, your health meter will look like this:

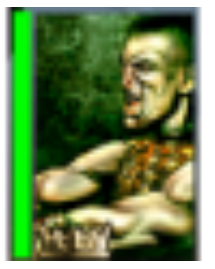

However, the color of the background will change such that at low health your health meter will look like this:

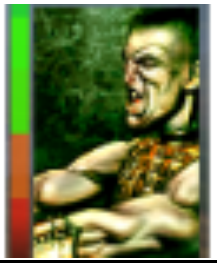

\section{Damage Flashes}

Each time a player deals damage to an enemy goblin, you will see the following animation around your character:

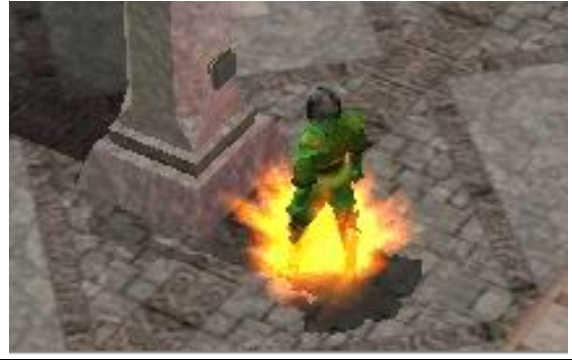

\section{Target Halo}

The player that is the current target of an enemy goblin will be designated with a "halo" as shown:

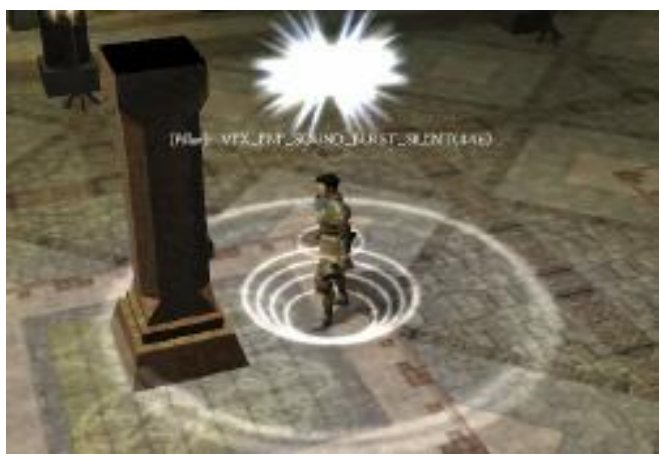




\section{Health Meter}

The background of your health meter will change depending on your current health level. When you are at full health, your health meter will look like this:

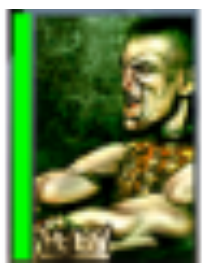

However, the color of the background will change such that at low health your health meter will look like this:

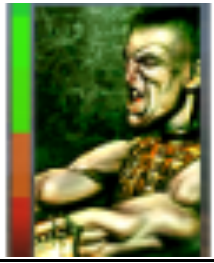

\section{Damage Flashes}

Each time a player deals damage to an enemy goblin, you will see the following animation around your character:

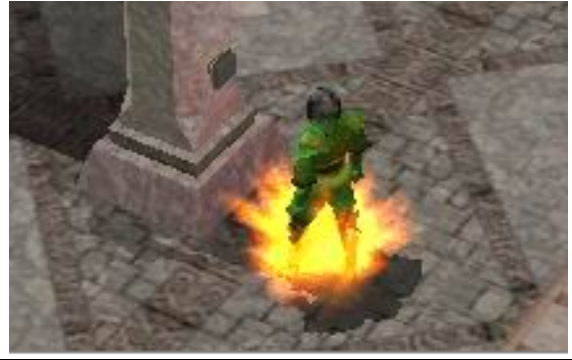

\section{Target Halo}

The player that is the current target of an enemy goblin will be designated with a "halo" as shown:

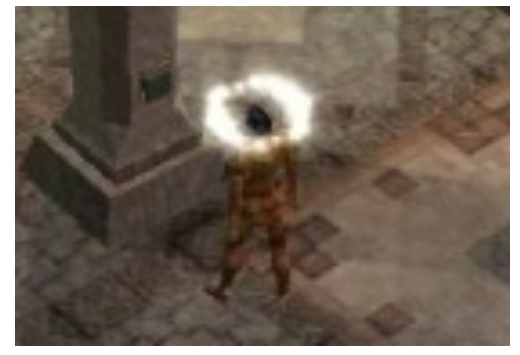




\section{Health Meter}

The background of yours and group members' health meters will change depending on the given players' current health level. For example, when you are at full health, your health meter will look like this:

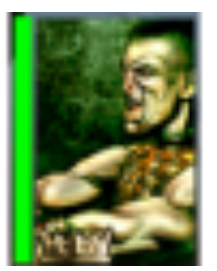

However, the color of the background will change such that at low health your health meter will look like this:

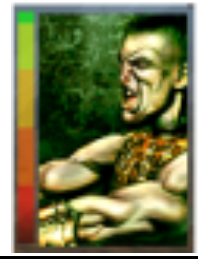

\section{Goblin LifeBar}

Each enemy goblin's current health will be represented with a lifebar that appears over its head like this:

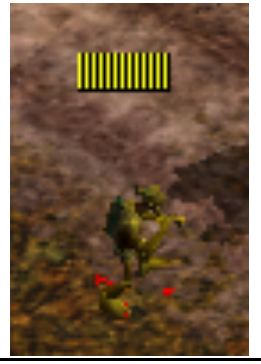

\section{Target Halo}

The player that is the current target of an enemy goblin will be designated with a "halo" as shown:

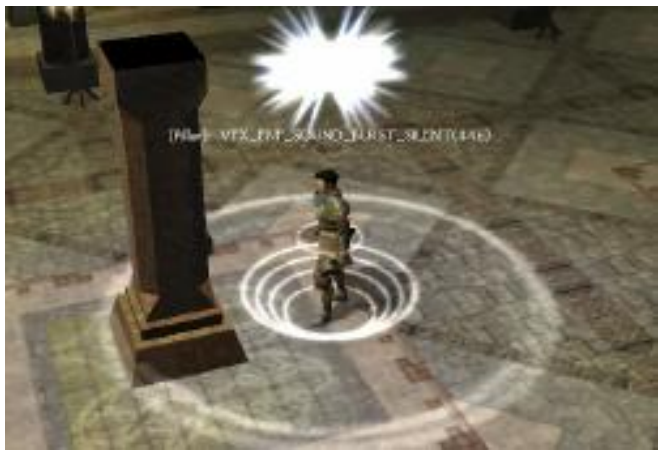




\section{APPENDIX 3}

\section{QUESTIONNAIRES}

Demographic Questionnaire

1. Gender: Male Female

2. Year of Birth:

3. Year: Freshman Sophomore Junior Senior Graduate

4. In the last week, have you played any console based (e.g., Playstation, Xbox, Nintendo DS) video game? Yes No

5. If yes, how many hours did you play?

6. In the last week, have you played any PC-based video games? Yes ___No

7. If yes, how many hours did you play?

8. Have you, at any point in the last five years, played console or PC based video games for more than an hour a day? Yes No

9. What genre of video games do you typically play (include both console and PC format):

Choose all that apply Adventure (e.g., Final Fantasy) Video Based Board or Card Games (e.g., Solitare) Fighting (e.g., Street Fighter) Massively Multiplayer Online Games (e.g., World of Warcraft) Music or Rhythm Games (e.g., Guitar Hero) Platform Games (e.g. Super Mario Bros.) Puzzle Games (e.g., Tetris) Racing (e.g., Mario Kart) Simulation (e.g., SimCity) Shooter (e.g., Halo) Strategy (e.g., Starcraft)

10. What genre of video game do you play most often? (include both console and PC format): Adventure (e.g., Final Fantasy) Video Based Board or Card Games (e.g., Solitare) Fighting (e.g., Street Fighter) 
Massively Multiplayer Online Games (e.g., World of Warcraft) Music or Rhythm Games (e.g., Guitar Hero)

Platform Games (e.g. Super Mario Bros.)

Puzzle Games (e.g., Tetris)

Racing (e.g., Mario Kart)

Simulation (e.g., SimCity)

Shooter (e.g., Halo)

Strategy (e.g., Starcraft)

11. Please estimate what percentage of your overall playing time is devoted to each genre (include both console and $P C$ format):

Adventure (e.g., Final Fantasy)

Video Based Board or Card Games (e.g., Solitare)

Fighting (e.g., Street Fighter)

Massively Multiplayer Online Games (e.g., World of Warcraft)

Music or Rhythm Games (e.g., Guitar Hero)

Platform Games (e.g. Super Mario Bros.)

___ Puzzle Games (e.g., Tetris)

Racing (e.g., Mario Kart)

Simulation (e.g., SimCity)

Shooter (e.g., Halo)

Strategy (e.g., Starcraft)

12. Have you ever played Neverwinter Nights or Neverwinter Nights 2 ? Yes No 
"During Task Survey"

\begin{tabular}{|l|l|l|l|l|l|l|l|}
\hline & $\begin{array}{c}\text { Strongly } \\
\text { Disagree }\end{array}$ & Disagree & $\begin{array}{c}\text { Moderately } \\
\text { Disagree }\end{array}$ & Undecided & $\begin{array}{c}\text { Moderately } \\
\text { Agree }\end{array}$ & Agree & $\begin{array}{c}\text { Strongly } \\
\text { Agree }\end{array}$ \\
\hline $\begin{array}{l}\text { Clayman is } \\
\text { responsible for } \\
\text { healing other } \\
\text { players. }\end{array}$ & & & & & & & \\
\hline $\begin{array}{l}\text { Clayman is best at } \\
\text { dealing damage to } \\
\text { monsters. }\end{array}$ & & & & & & & \\
\hline $\begin{array}{l}\text { Clayman is best at } \\
\text { absorbing damage } \\
\text { from monsters. }\end{array}$ & & & & & & & \\
\hline $\begin{array}{l}\text { Clayman is worst } \\
\text { at dealing damage } \\
\text { to monsters. }\end{array}$ & & & & & & & \\
\hline $\begin{array}{l}\text { Clayman has the } \\
\text { most powerful } \\
\text { attacks on } \\
\text { monsters. }\end{array}$ & & & & & & & \\
\hline $\begin{array}{l}\text { Clayman has the } \\
\text { most health } \\
\text { points. }\end{array}$ & & & & & & & \\
\hline $\begin{array}{l}\text { Clayman is the } \\
\text { tallest player. }\end{array}$ & & & & & & & \\
\hline $\begin{array}{l}\text { Clayman is the } \\
\text { fastest player. }\end{array}$ & & & & & & & \\
\hline $\begin{array}{l}\text { Clayman is the } \\
\text { player that uses } \\
\text { magic spells. }\end{array}$ & & & & & & & \\
\hline
\end{tabular}




\begin{tabular}{|c|c|c|c|c|c|c|c|}
\hline & $\begin{array}{l}\text { Strongly } \\
\text { Disagree }\end{array}$ & Disagree & $\begin{array}{c}\text { Moderately } \\
\text { Disagree }\end{array}$ & Undecided & $\begin{array}{c}\text { Moderately } \\
\text { Agree }\end{array}$ & Agree & $\begin{array}{c}\text { Strongly } \\
\text { Agree }\end{array}$ \\
\hline $\begin{array}{l}\text { Kheldara is } \\
\text { responsible for } \\
\text { healing other } \\
\text { players. }\end{array}$ & & & & & & & \\
\hline $\begin{array}{l}\text { Kheldara is best } \\
\text { dealing damage } t \\
\text { monsters. }\end{array}$ & & & & & & & \\
\hline $\begin{array}{l}\text { Kheldara is best } \\
\text { absorbing damag } \\
\text { from monsters. }\end{array}$ & & & & & & & \\
\hline $\begin{array}{l}\text { Kheldara is wors } \\
\text { at dealing damag } \\
\text { to monsters. }\end{array}$ & & & & & & & \\
\hline $\begin{array}{l}\text { Kheldara has the } \\
\text { most powerful } \\
\text { attacks on } \\
\text { monsters. }\end{array}$ & & & & & & & \\
\hline $\begin{array}{l}\text { Kheldara has the } \\
\text { most health } \\
\text { points. }\end{array}$ & & & & & & & \\
\hline $\begin{array}{l}\text { Kheldara is the } \\
\text { tallest player. }\end{array}$ & & & & & & & \\
\hline $\begin{array}{l}\text { Kheldara is the } \\
\text { fastest player. }\end{array}$ & & & & & & & \\
\hline $\begin{array}{l}\text { Kheldara is the } \\
\text { player that uses } \\
\text { magic spells. }\end{array}$ & & & & & & & \\
\hline
\end{tabular}




\begin{tabular}{|l|l|l|l|l|l|l|}
\hline & $\begin{array}{c}\text { Strongly } \\
\text { Disagree }\end{array}$ & Disagree & $\begin{array}{c}\text { Moderately } \\
\text { Disagree }\end{array}$ & Undecided & $\begin{array}{c}\text { Moderately } \\
\text { Agree }\end{array}$ & $\begin{array}{c}\text { Agree } \\
\text { Strongly } \\
\text { Agree }\end{array}$ \\
\hline $\begin{array}{l}\text { Toru is responsible } \\
\text { for healing other } \\
\text { players. }\end{array}$ & & & & & & \\
\hline $\begin{array}{l}\text { Toru is best at } \\
\text { dealing damage to } \\
\text { monsters. }\end{array}$ & & & & & & \\
\hline $\begin{array}{l}\text { Toru is best at } \\
\text { absorbing damage } \\
\text { from monsters. }\end{array}$ & & & & & & \\
\hline $\begin{array}{l}\text { Toru is worst at } \\
\text { dealing damage to } \\
\text { monsters. }\end{array}$ & & & & & & \\
\hline $\begin{array}{l}\text { Toru has the most } \\
\text { powerful attacks } \\
\text { on monsters. }\end{array}$ & & & & & & \\
\hline $\begin{array}{l}\text { Toru has the most } \\
\text { health points. }\end{array}$ & & & & & & \\
\hline $\begin{array}{l}\text { Toru is the tallest } \\
\text { player. }\end{array}$ & & & & & & \\
\hline $\begin{array}{l}\text { Toru is the fastest } \\
\text { player. } \\
\text { soru is the player } \\
\text { spells. }\end{array}$ & & & & & & \\
\hline
\end{tabular}


Role Ambiguity Scale

\begin{tabular}{|c|c|c|c|c|c|c|c|}
\hline Question & $\begin{array}{l}\text { Strongly } \\
\text { Disagree }\end{array}$ & Disagree & $\begin{array}{c}\text { Moderately } \\
\text { Disagree }\end{array}$ & Undecided & $\begin{array}{l}\text { Moderately } \\
\text { Agree }\end{array}$ & Agree & $\begin{array}{c}\text { Strongly } \\
\text { Agree }\end{array}$ \\
\hline $\begin{array}{l}\text { I had clear, planned } \\
\text { goals and objectives } \\
\text { for the tasks that } \\
\text { my player } \\
\text { completed. }\end{array}$ & & & & & & & \\
\hline $\begin{array}{l}\text { I felt certain about } \\
\text { how much authority } \\
\text { I had. }\end{array}$ & & & & & & & \\
\hline $\begin{array}{l}\text { There was a lack of } \\
\text { rules and divisions } \\
\text { of responsibilities to } \\
\text { help me. }\end{array}$ & & & & & & & \\
\hline $\begin{array}{l}\text { I knew that I had } \\
\text { divided my time } \\
\text { properly. }\end{array}$ & & & & & & & \\
\hline $\begin{array}{l}\text { I knew what my } \\
\text { responsibilities } \\
\text { were. }\end{array}$ & & & & & & & \\
\hline $\begin{array}{l}\text { I had to "feel my } \\
\text { way" in performing } \\
\text { my part in the } \\
\text { game. }\end{array}$ & & & & & & & \\
\hline $\begin{array}{l}\text { I felt certain how I } \\
\text { would be evaluated } \\
\text { by my group } \\
\text { members. }\end{array}$ & & & & & & & \\
\hline $\begin{array}{l}\text { I had just the right } \\
\text { amount of tasks to } \\
\text { do. }\end{array}$ & & & & & & & \\
\hline $\begin{array}{l}\text { I knew exactly was } \\
\text { expected of me. }\end{array}$ & & & & & & & \\
\hline $\begin{array}{l}\text { I received an } \\
\text { assignment without } \\
\text { adequate } \\
\text { information and } \\
\text { player abilities to } \\
\text { execute it. }\end{array}$ & & & & & & & \\
\hline $\begin{array}{l}\text { The explanation was } \\
\text { clear of what had to } \\
\text { be done. }\end{array}$ & & & & & & & \\
\hline $\begin{array}{l}\text { I completed } \\
\text { unnecessary tasks. }\end{array}$ & & & & & & & \\
\hline
\end{tabular}




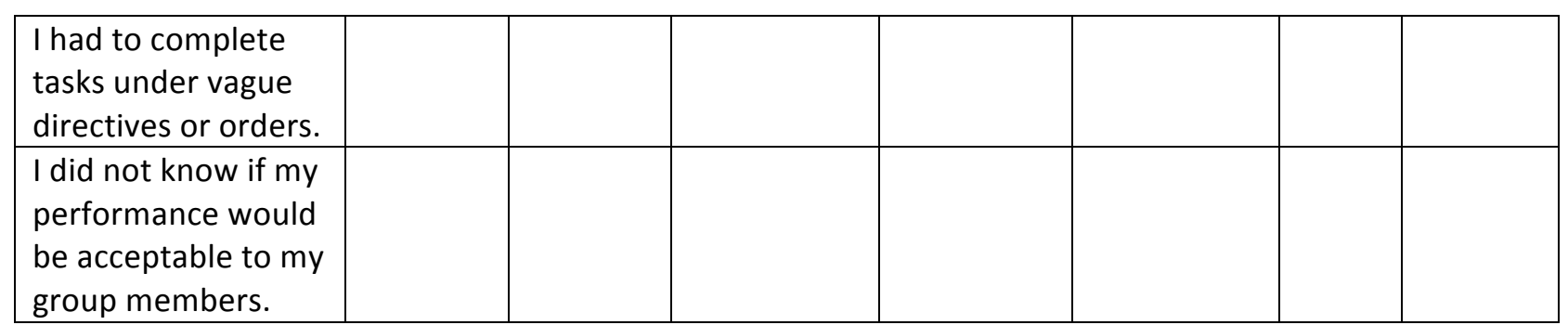


Interpersonal Attraction Scale

Please answer the following questions about the person who played Kheldara ${ }^{1}$ (the avatar wearing red clothes)

\begin{tabular}{|c|c|c|c|c|c|c|c|}
\hline Questions & $\begin{array}{l}\text { Strongly } \\
\text { Disagree }\end{array}$ & $\begin{array}{l}\text { Moderately } \\
\text { Disagree }\end{array}$ & Disagree & Undecided & Agree & $\begin{array}{c}\text { Moderately } \\
\text { Agree }\end{array}$ & $\begin{array}{c}\text { Strongly } \\
\text { Agree }\end{array}$ \\
\hline $\begin{array}{l}\text { I think he (she) } \\
\text { could be a friend of } \\
\text { mine }\end{array}$ & & & & & & & \\
\hline $\begin{array}{l}\text { It would be difficult } \\
\text { to meet and talk } \\
\text { with him (her) }\end{array}$ & & & & & & & \\
\hline $\begin{array}{l}\text { He (she) just } \\
\text { wouldn't fit into my } \\
\text { circle of friends }\end{array}$ & & & & & & & \\
\hline $\begin{array}{l}\text { We could never } \\
\text { establish a personal } \\
\text { friendship with each } \\
\text { other. }\end{array}$ & & & & & & & \\
\hline $\begin{array}{l}\text { I would like to have } \\
\text { a friendly chat with } \\
\text { him (her). }\end{array}$ & & & & & & & \\
\hline $\begin{array}{l}\text { He (she) is a typical } \\
\text { goof-off when } \\
\text { assigned a job to } \\
\text { do. }\end{array}$ & & & & & & & \\
\hline $\begin{array}{l}\text { I have confidence in } \\
\text { his (her) ability to } \\
\text { get the job done. }\end{array}$ & & & & & & & \\
\hline $\begin{array}{l}\text { If I wanted to get } \\
\text { things done I could } \\
\text { probably depend on } \\
\text { him (her). }\end{array}$ & & & & & & & \\
\hline $\begin{array}{l}\text { I couldn't get } \\
\text { anything } \\
\text { accomplished with } \\
\text { him (her). }\end{array}$ & & & & & & & \\
\hline $\begin{array}{ll}\text { He (she) } & \text { would be a } \\
\text { poor } & \text { problem } \\
\text { solver. } & \end{array}$ & & & & & & & \\
\hline
\end{tabular}

\footnotetext{
${ }^{1}$ This shows the Interpersonal Attraction Scale questions for one group member, but each participant answered this survey for both of their other group members. The group member name and avatar description were altered for each group member.
} 


\section{APPENDIX 4}

\section{CODING SCHEME}

\section{Task-Related Statements (Code: TAS)}

Task-Related Statements represent utterances related to players' actions within the game. Includes the following:

- Strategy (Code: STR) represents utterances related to the formation and the adjustment of players' coordination in order to maximize the effectiveness of the group. Includes the following:

- Explicit Statement (Code: EXP) represents utterances related to the general preparation of the group. Includes the following:

- Ready Check (Code: RDY)

- "Ready?"

- "I'm ready now"

- Suggestions for coordination (Code: SUG)

- "ok go"

- "run away!"

- Question about strategy (Code: QAS)

- should we alternate who attacks first?

- Notification of an upcoming enemy (Code: NOT)

- "ok goblin ahead"

- Acknowledgement (Code: ACK) represents utterances related to players' understanding of an earlier statement. Acknowledgments should not serve any other function. Includes the following:

- Positive Acknowledgements (Code: PAC)

- "ok"

- Negative Acknowledgements(Code: NAC)

- "wait what?"

- Resting (Code: RES) represents the utterances related to the maintenance of the group by resting. Includes the following:

- Asking for a moment to rest / Notification of rest (Code: SEL)

- "I have to rest"

- Asking others to take rest/asking others if they need a rest (Code: OTH)

- "ok everyone rest"

- Location (Code: LOC) represents utterances related to the discussion of checking where each player is in the game environment. Includes the following:

- Asking where the player is (Code: WHE)

- "where are you clayman?"

- Asking player to relocate (Code: REL)

- Healing (Code: HEA) represents utterances related to the activity of healing other players and the activity of being healed. Does NOT include utterances related to which player has healing abilities. Includes the following:

- Requesting heals (Code: REQ)

- "can you heal me"

- Offering heals (Code: OFH) 
- "who needs heal?"

- Response to offers (Code: RTO)

- "im good not me"

- Game Understanding (Code: UND) represents utterances related to the players' level of competency in playing the game. Includes the following:

- Learning Curve (Code: CUR) represent utterances related to players' actions and expressions representing their level of understanding the mechanics of the game. Includes the following:

- Positive Understanding

- Positive explicit reference (Code: PCR)

- "I cant rest if there are monseters near me"

- Assisting of others (Code: AST)

- "oh press $f$... six"

- Negative Understanding

- Negative explicit reference (Code: NCR)

- "I'm so bad at moving"

- Question about gameplay (Code: QUE)

○ "is there friendly fire in this game?"

- Apology/contrition (Code: APO)

○ "sorry got distracted"

\section{Role Understanding Statements (Code: ROL)}

Role Understanding Statements represent utterances related to players' level of competency in correctly understanding their and other group members' roles in the game. Includes the following:

- Role Understanding about Self

- Positive understanding about self role

- Positive explicit reference about self role (Code: PRS)

- "I can only cast like 2 spells per battle just fyi"

- Negative understanding about self role

- Negative explicit reference about self role (Code: NRS)

- "I can't heal??"

- Question about self role (Code: QRS)

- "can I parry?"

- Role Understanding about Others

- Positive Understanding about others' roles

- Positive explicit reference about others' roles (Code: PRO)

- "you are the healer person so you have to help us restore our energy or w/e"

- Assisting others with role (Code: HRO)

- "click F3 for your special spell"

- Negative understanding about others' roles

- Negative explicit reference about others' role (Code: NRO)

- "toru can use magic spells"

- Question about others' role (Code: QRO)

- "can you parry?" 


\section{Socio-Emotional Statements (Code: SOC)}

Socio-Emotional Statements represent utterances related to players' expressions within the game. Includes the following:

- Positive Expression (Code: PEX) represents utterances related to players' statements with positive attitude.

- Negative Expression (Code: NEX) represents utterances related to players' dissatisfaction or irritation with the experience of playing the game.

- Frustration about self or others' roles (Code: FRL) represents utterances relating to roles, ability distribution, or specific abilities.

- "it sucks that I have to rest before I can heal more"

\section{Experiment Statements (Code: STU)}

Experiment statements represent utterances related to elements of the experimental manipulation or structure (as opposed to the game or task itself). Includes the following:

- Display (Code: DIS) represents utterances about the UI display elements.

- "what does the white circle mean?"

- Survey (Code: SUR) represents utterances about the during task survey.

- "i don't know how to answer some of the survey questions"

- Pauses (Code: PAU)

○ "why is the game paused?"

\section{Tangential Statements (Code: TAN)}

Tangential Statements represent utterances related to players' actions or expressions that are not directly related to the experiment itself. Includes the following:

- Environment (Code: ENV) represents utterances related to players' statements about the various features in the game that are not related to the experiment.

- Off-topic (Code: OFF) represents utterances related to players' statements and responses that are entirely unrelated to both the game and the experiment. 


\section{References}

Baltes, B.B., Dickson, M.W., Sherman, M.P., Bauer, C.C., and LaGanke, J.S. (2002). Computer Mediated Communication and Decision Making: A Meta-Analysis. Organizational Behavior and Human Decision Processes, 87(1), 156-179.

Bardzell, S., Bardzell, J., Pace, T., and Reed, K. (2008). Blissfully Productive: Grouping and Cooperation in World of Warcraft Instance Runs. In the conference proceedings of Computer Supported Cooperative Work, (pp. 357-360). November 8-12, 2008, San Diego, California.

Bechky, B. (2006). Gaffers, Gofers, and Grips: Role-Based Coordination in Temporary Organizations. Organization Science, 17(1), pp. 3-21.

Beehr, T.A., Walsh, J.T., and Taber, T.D. (1976). Relationship of Stress to Individually and Organizationally Valued States: Higher Order Needs as a Moderator. Journal of Applied Psychology, 61, 41-47.

Beauchamp, M.R., Bray, S.R., Eys, M.A., and Carron, A.V. (2002). Role Ambiguity, Role Efficacy, and Role Performance: Multidimensional and Mediational Relationships within Interdependent Sports Teams. Group Dynamics: Theory, Research and Practice, 6, 229242.

Benford, S., Bederson, B. et al. (2001). Designing Storytelling Technologies to Encourage Collaboration between Young Children. Proceedings of CHI, 556-563.

Biddle, B., and Thomas, E. (1979). Role Theory: Expectations, Identities, and Behaviors. Academic Press.

Bly, S.A., Harrison, S.R., and Irwin, S. (1993). Media Spaces: Bringing People Together in a Video, Audio, and Computing Environment. Communications of the ACM, 26(1), 28-47. 
Bostrom, R.P. (1980). Role conflict and ambiguity: Critical variables in the MIS user-designer relationship. In the Conference Proceedings of SIGCPR, 88-115.

Boudreau, K. (2005). Role Theory: The Line between Roles as Design and Socialization in EverQuest. Proceedings of DiGRA, 2005.

Caplan, R.D. and Jones, K.W. (1975). Effects of work load, role ambiguity, and type A personality on anxiety, depression, and heart rate. Journal of Applied Psychology, 60, 713-719.

Carstensen, P.H. and Schmidt, K. (1999). Computer Supported Cooperative Work: New Challenges to System Design. In Kenji Itoh (Ed.) Handbook of Human Factors.

Chen, N. (2009). Communication, Coordination, and Camaraderie in World of Warcraft. Games and Culture, 4(1), pp. 47-73.Clark, H. (1996). Using Language. Cambridge: Cambridge University Press.

Cummings J., Finholt, T., Foster, I., \& Kesselman, C. (2008). Beyond being there: A blueprint for advancing the design, development, and evaluation of virtual organizations. Building Effective Virtual Organizations workshop.

Dabbish, L., Kraut, R.E. (2004). Controlling interruptions: awareness displays and social motivation for coordination. Proceedings of CSCW, 182-191.

Dougherty, T.W. and Prichard, R.D. (1985). The measurement of role variables: Exploratory examination of a new approach. Organizational Behavior and Human Decision Processes, 35(2), 141-155.

Ducheneaut, N., Yee, N., Nickell, E., and Moore, R.J. (2006). "Alone Together? Exploring the Social Dynamics of Massively Multiplayer Games." In the conference proceedings on 
human factors in computing systems (CHI 2006) (pp. 407-416). April 22-27, Montreal, Canada

Endsley, M. (1995). Toward a Theory of Situation Awareness in Dynamic Systems. Human Factors, 37 (1). pp. 32-64.

Fisher, C.D. and Gitelseon, R. (1983). A Meta-analysis of the Correlates of Role Conflict and Ambiguity. Journal of Applied Psychology, 68(2), 320-333.

Glaser, B.G., Strauss, A. (1967). Discovery of Grounded Theory: Strategies for Qualitative Research. Soc. Press.

Goffman, E. (1961). Encounters: Two Studies in the Sociology of Interaction. Bobbs-Merrill, Indianapolis, IN.

Graen, G. (1976). Role-making processes within complex organizations. In M.D. Dunnette (Ed.), Handbook of Industrial Organizational Psychology. Chicago: Rand McNally.

Gutwin, C. and Greenberg, S. (2002). A Descriptive Framework of Workspace Awareness for Real-Time Groupware. Computer Supported Cooperative Work, 11(3-4), 411-446.

Guzdial, M. Rick, J. and Kerimbaev, B. (2000). Recognizing and supporting roles in CSCW. Proceedings of CSCW, 261-268.

Heath, C. and Luff, P. (1992). Collaboration and control: Crisis management and multimedia technology in London Underground Line Control Rooms. Computer Supported Cooperative Work, 1 (1-2), 69-94.

Hussain, T.S. and Ferguson, W. Efficient development of large-scale military training environments using a multi-player game. 2005 Fall Simulation Interoperability Workshop, (2005), 421-431. 
Hughes, E. C. (1958). Men and Their Work. The Free Press, Glencoe, IL.

Hutchins, E. (1990). The Technology of Team Navigation. In J. Galegher, R. Kraut, and C. Egido (Eds.): Intellecutal Teamwork: Social and Technological Foundations of Cooperative Work, pp. 191-220. Hillsdale, NJ: Lawrence Erlbaum.

Johnson, D. W., \& Johnson, F. P. (1997).Joining together: Group theory and group skills(6th ed.). Boston: Allyn \& Bacon.

Jones, G.R. (2007). Organizational Theory, Design and Change (Fifth Edition). Pearson Education, Inc: Upper Saddle River, New Jersey.

Judeh, M. (2011) Role Ambiguity and Role Conflict as Mediators of the Relationship between Orientation and Organizational Commitment. International Business Research, 4(3), 171181.

Kahn, R., Wolfe, D., Quinn, R., Snoek, D., and Rosenthal, R. (1964). Organizational Stress: Studies in Role Conflict and Ambiguity. John Wiley and Sons, Inc.: New York.

Lichtman, C.M., and Hunt, R.G. (1973). Personality and Organization Theory: A Review of Some Conceptual Literature. In W.W. Scott and L.L. Cummings (Eds.), Readings in Organizational Behavior and Human Performance. Homewood, Ill.: Irwin.

Mintzberg, H. (1994). The Rise and Fall of Strategic Planning: Reconceiving the Roles for Planning, Plans, Planners. Englewood Cliffs, NJ: Prentice-Hall.

Nardi, B. and Harris, J. (2006). "Strangers and Friends: Collaborative Play in World of Warcraft." In the proceedings of Computer Supported Cooperative Work, November 4-8, 2006, Banff, Alberta, Canada.

Neisser, U. (1976). Cognition and Reality. San Francisco: W.H. Freeman. 
Rizzo, J.R., House, R.J., and Lirtzman, S.I. (1970). Role Conflict and Ambiguity in Complex Organizations. Administration Science Quarterly, 15, 150-163.

Schmidt, K. (2002). The Problem with 'Awareness': Introductory Remarks of 'Awareness in CSCW.' Computer Supported Cooperative Work, 11, 285-298.

Sins, P.H.M., Savelsbergh, E.R., van Joolingen, W.R., and van Hout-Wolters, B.H.A.M. (2011). Effects of Face-to-face versus Chat Communication on Performance in a Collaborative Inquiry Modeling Task. Computers and Education, 56, 379-387.Slatterya, J.P., Selvarajanb, T., and Andersonic, J.E. (2008). The Influences of New Employee Development Practices upon Role Stressors and Work-related Attitudes of Temporary Employees. The International Journal of Human Resource Management, 18(4), 317-328.

Smith, R., Hixon, R., and Horan, B. (1998). Supporting Flexible Roles in a Shared Space. Proceedings of CSCW, 197-206.

Sonnenwald, D.H, Maglaughlin, K.L., and Whitton, M.C. (2004). Designing to support situation awareness across distances: an example from a scientific collaboratory. Information Processing and Management: an International Journal, 40(6), 989-1011.

Stefik, M., Bobrow, D., Foster, G., Lanning, S., and Tatar, D. (1987). "WYSIWIS Revised: Early Experiences with Multiuser Interfaces.” ACM Transactions on Office Information Systems, 5(2), 147-167.

Strauss, A. (1985). Work and the division of labor. Sociological Quarterly, 29 (1), pp. 1-19. 
Straus, S.G. and McGrath, J.E. (1994) Does the medium matter? The interaction of task type and technology on group performance and member reactions. Journal of Applied Psychology, 79(1), 87-97.

Van Sell, M., Brief, A.P, and Schuler, R.S. (1981). Role Conflict and Role Ambiguity: Integration of the Literature and Directions for Future Research. Human Relations, 34(1), 43-71.

Williams, D., Ducheneaut, N., Xiong, L., Zhang, Y., Yee, N., and Nickell, E.(2006). "From tree house to barracks: The social life of guilds in World of Warcraft." Games \& Culture, 1(4), pp. 338-361.

Yee, N. (2006a). "The Demographics, Motivations, and Derived Experiences of Users of Massively Multi-User Online Graphical Environments.) Presence, 15(3), pp. 309-329

Yee, N. (2006b). "The Labor of Fun: How Video Games Blur the Boundaries of Work and Play." Games and Culture, 1(1), pp. 68-71.

Zhu, H. (2004). From WYSIWIS to WYSINWIS: Role-Based Collaboration. Proceedings of IEEE, 5441- 5446. 